\title{
Site Selective Detection of Methane Dissociation on Stepped Pt Surfaces
}

\author{
A. Gutiérrez-González ${ }^{1} \cdot$ M. E. Torio ${ }^{2,3} \cdot$ H. F. Busnengo ${ }^{3,4} \oplus \cdot$ R. D. Beck ${ }^{1}$
}

(c) Springer Science+Business Media, LLC, part of Springer Nature 2019

\begin{abstract}
We report a combined experimental and theoretical study comparing methane dissociation on three different platinum surfaces $\operatorname{Pt}(111), \operatorname{Pt}(211)$, and $\operatorname{Pt}(110)-(1 \times 2)$. Reflection absorption infrared spectroscopy (RAIRS) was used to detect chemisorbed methyl species formed by dissociative chemisorption of $\mathrm{CH}_{4}$ on specific surface sites and to measure surfacesite-specific sticking coefficients of $\mathrm{CH}_{4}$ on the terrace, step, and ridge sites as function of incident translational energy. Methane dissociation is observed to be direct on all sites and diffusion of the chemisorbed methyl species is absent for surface temperature below $150 \mathrm{~K}$. The experimental data are compared with the results of density functional (DFT) calculations that give minimum energy barriers for $\mathrm{CH}_{4}$ chemisorption that properly account for the experimental relative site-specific reactivities. Also in agreement with experiments, DFT results predict a negligible effect of co-adsorbed $\mathrm{H}$ and $\mathrm{CH}_{3}$ species on the vibrational frequency of a methyl group chemisorbed on terrace and step sites of $\operatorname{Pt}(211)$. However, the origin of the red-shift of the RAIRS peak of $\mathrm{CH}_{3}$ chemisorbed on terrace sites compared with that on step sites of $\mathrm{Pt}(211)$ remains elusive and still demands further investigation.
\end{abstract}

Keywords Pt surfaces $\cdot$ Methane $\cdot$ RAIRS $\cdot$ DFT

\section{Introduction}

The dissociative chemisorption of methane on a metal catalyst is known to be the rate-limiting step in the steamreforming process, which is the principal industrial source of molecular hydrogen [1]. The hydrogen is needed for the synthesis of ammonia as well for combustion in fuel cells

H. F. Busnengo

busnengo@ifir-conicet.gov.ar

$\triangle$ R. D. Beck

rainer.beck@epfl.ch

1 Laboratoire de Chimie Physique Moléculaire (LCPM), École Polytechnique Fédérale de Lausanne (EPFL), 1015 Lausanne, Switzerland

2 Centro Internacional Franco Argentino de Ciencias de la Información y de Sistemas (CIFASIS), CONICET-UNR, Bv. 27 de Febrero 210 bis (2000), Rosario, Argentina

3 Facultad de Ciencias Exactas, Ingeniería y Agrimensura, Universidad Nacional de Rosario, Av. Pellegrini 250 (2000), Rosario, Argentina

4 Instituto de Física Rosario (IFIR), CONICET-UNR, Bv. 27 de Febrero 210 bis (2000), Rosario, Argentina among other applications. Due to its importance, the catalytic activation of methane has been extensively studied in surface-science [2-5].

A number of experimental and theoretical studies have explored the effect of translational and vibrational energy on the dissociation of methane for different catalytically active surfaces [6-14]. Quantum state resolved molecular beam studies proved methane chemisorption to be modespecific, where the dissociation probability depends not simply on the reactant's total vibrational energy but differs for different isoenergetic vibrational modes by up to an order of magnitude [11]. Therefore statistical theories, assuming complete randomization of the initial vibrational energy prior to dissociation on the catalyst surface, do not provide an accurate description of the reaction dynamics for methane chemisorption [15-17]. In contrast, dynamical models including quasi-classical and quantum theories are needed to accurately describe the energy flow and activation of the methane molecule approaching the metal catalyst [18-22].

Significant effort has been put in the collaboration between theory and experiment with the goal to arrive at a predictive understanding of this reaction in order to find optimal catalytic conditions for the dissociation of methane 
$[23,24]$. However, most surface science studies performed so far on methane dissociation have used single crystals cut along high symmetry crystallographic directions, which are not fully representative of the surface of real catalysts. The structural difference between the atomically smooth single crystals often used in surface science experiments and real catalysts containing defects such as steps, kinks and vacancies is known as the "structure gap" [25-27].

One way to start closing this structure gap is to study the role of a specific defect by using single crystals cut in ways to expose a well-defined arrangement of "defect" sites such as steps and kinks. One of the first such studies concerning methane dissociation on a stepped surface was reported by Gee et al. [28] who probed methane dissociation on a $\operatorname{Pt}(533)$ surface which consists of a periodic array of (111) terrace and (100) step sites. By comparing the reactivity of $\mathrm{CH}_{4}$ on the stepped $\mathrm{Pt}(533)$ with a flat $\mathrm{Pt}(111)$ they observed a higher dissociation probability on the stepped surface, which they attributed to the presence of the (100) steps. However, the product detection methods that they used (King and Wells method [29] and $\mathrm{O}_{2}$ titration) were not surface-site-specific and only measured total reactivity averaged over all surface sites present on the sample. In order to extract the reactivity of the step sites, the authors had to assume equal reactivity for the terrace sites on $\operatorname{Pt}(533)$ and $\mathrm{Pt}(111)$ which is not necessarily correct [30].

Papp et al. [31] studied methane dissociation on the stepped surfaces $\operatorname{Pt}(355)$ and $\operatorname{Pt}(322)$ using X-ray photoelectron spectroscopy (XPS). Both surfaces consist of five atoms wide (111) terraces separated by (111) and (100) steps, respectively. Methane reactivity was measured by recording carbon XPS line profiles following methane dissociation on $\mathrm{Pt}(111), \operatorname{Pt}(355)$ and $\mathrm{Pt}(322)$. The XPS signal was deconvoluted into a series of peaks to resolve the contribution from terrace and step sites as well as due to $\mathrm{C}-\mathrm{H}$ fragments produced by the intense $\mathrm{X}$-ray radiation. Comparison of the signal ratios for the $\mathrm{CH}_{3}$ peaks assuming identical vibrational fine structure for the terraces of the three surfaces indicated a similar reactivity for the step and the terrace sites, in contradiction with the study of Gee et al. [28]. However, on the stepped surfaces, methyl was found to occupy mostly the steps of the surface with about only $10-20 \%$ of the methyl coverage on the terraces. Assuming a similar reactivity for the terraces of the stepped surface and the terraces of the flat $\operatorname{Pt}(111)$ surface, the authors concluded that the higher coverage on the steps sites was due to a rapid diffusion to the step sites of the methyl groups initially formed on terrace sites at a surface temperature of $120 \mathrm{~K}$.

The discrepancies between these two studies and the lack of further studies concerning the role of "defect sites" on the dissociation of methane on metals motivated us to perform a systematic study of this reaction on differently coordinated surface sites. The EPFL group has recently demonstrated the surface-site-specific detection of chemisorbed methyl species on the step and terrace sites of $\mathrm{Pt}(211)$ [32] by reflection absorption infrared spectroscopy (RAIRS). RAIRS detection was used to measure the reaction probabilities for $\mathrm{CH}_{4}$ dissociation on the steps and terraces of $\operatorname{Pt}(211)$ and compared to theoretical predictions obtained by the Reaction Path Hamiltonian (RPH) method for methane chemisorption based on density functional theory (DFT) developed by the group of Bret Jackson [32-34]. Both experiment and theory showed that the reactive sticking coefficients are higher on the steps than on the terraces of $\operatorname{Pt}(211)$ due to a lower dissociation barrier by at least $30 \mathrm{~kJ} / \mathrm{mol}$ for steps compared to terraces. The experiments also showed that the dissociation is direct on both steps and terraces of $\operatorname{Pt}(211)$ and that diffusion of the methyl species from the terraces to the steps does not occur at $T_{\mathrm{s}}=120 \mathrm{~K}$ in agreement with a calculated diffusion barrier of $65 \mathrm{~kJ} / \mathrm{mol}$ [32].

DFT calculations are an important complement to surface site resolved experiments, in particular when the dissociation reaction can take place on several different adsorption sites. DFT can help to determine the adsorption geometry of methyl groups on different adsorption sites, aid in the assignment of the observed vibrational frequencies, and estimate the effect of lateral interactions between methyl groups, and the presence of co-adsorbed $\mathrm{H}$ atoms. To date, DFT calculations have been extensively used to investigate the stability of $\mathrm{CH}_{3}$ on different adsorption sites of low- and some highMiller-indices surfaces of Pt [32, 35-42]. All these studies agree that $\mathrm{CH}_{3}$ adsorbs preferentially on top of a single $\mathrm{Pt}$ atom (i.e. top site) and that for stepped surfaces, the adsorption is more stable on Pt step atoms than on the terraces [32, 40, 41]. This stronger interaction with lower-coordination $\mathrm{Pt}$ atoms also entails a lower activation energy for $\mathrm{CH}_{4}$ dissociation on step-edge sites than on the terrace sites, in line with larger sticking coefficients on the steps observed in our experiments [32].

Predicting vibrational frequencies of chemisorbed species by DFT is more challenging than the calculation of adsorption energies but can be very useful in order to confirm the assignment of the RAIR spectra to different absorption sites. For the $\mathrm{CH}_{3}$ (ads) on $\mathrm{Pt}(211)$, we assigned the peak at $2886 \mathrm{~cm}^{-1}$ to the symmetric $\mathrm{C}-\mathrm{H}$ stretch of $\mathrm{CH}_{3}$ (ads) on terrace sites. A second peak, shifted by $17 \mathrm{~cm}^{-1}$ to higher frequency was assigned to $\mathrm{CH}_{3}$ (ads) on the step sites, based on the comparison with the RAIR spectrum for $\mathrm{CH}_{3}$ (ads) on $\mathrm{Pt}(111)$ as well as the observed $\mathrm{CH}_{3}$ (ads) uptake which is much faster on the step than on the terrace sites [32]. A simple argument based on the stronger binding of $\mathrm{CH}_{3}$ (ads) on the step sites, suggests the opposite, i.e. a red-shift for the step compared to the terrace site similar to what is observed for CO species adsorbed on the step and terrace sites of $\operatorname{Pt}(211)$ [43]. Thus, the observed red-shift of the peak of 
$\mathrm{CH}_{3}$ (ads) on the terrace with respect to the step is somewhat surprising.

Interestingly, the frequency of the symmetric $\mathrm{C}-\mathrm{H}$ stretch mode of $\mathrm{CH}_{3}$ on $\mathrm{Pt}(111)$ in the fcc-hollow sites is predicted by DFT to be lower than on the top sites, despite the $\mathrm{CH}_{3}$-surface bond in the former site being weaker than in the latter. Michaelides and $\mathrm{Hu}$ [36] concluded that the softening of the $\mathrm{C}-\mathrm{H}$ bonds for $\mathrm{CH}_{3}$ located on a fcc-hollow site is due to their stronger interaction with surface $\mathrm{Pt}$ atoms. For $\mathrm{CH}_{3}$ (ads) in the fcc-hollow sites, the $\mathrm{C}-\mathrm{H}$ bonds are closer to the $\mathrm{Pt}$ atoms than for $\mathrm{CH}_{3}$ chemisorbed on the top sites. A similar argument might explain the red-shift of the frequency of the symmetric stretching mode of $\mathrm{CH}_{3}(\mathrm{ads})$ on a terrace site of $\mathrm{Pt}(211)$ with respect to $\mathrm{CH}_{3}$ (ads) on a stepedge site, since in the latter case the $\mathrm{C}-\mathrm{H}$ bonds are expected to be at a larger distance from the Pt surface atoms [32].

In this work, we extend our experimental studies for methane dissociation on $\operatorname{Pt}(111)$ and $\operatorname{Pt}(211)$, to $\mathrm{Pt}(110)$ $(1 \times 2)$ using the site-specific detection capabilities of RAIRS for chemisorbed $\mathrm{CH}_{3}$ (ads) species reported by us recently [32, 44]. RAIRS detection of $\mathrm{CH}_{3}$ (ads) allows for surface-site-specific reactivity measurements for methane dissociation on platinum surfaces. We also present DFT results of adsorption energies, vibrational frequencies, and minimum energy barriers $\left(\mathrm{E}_{\mathrm{b}}\right)$ for $\mathrm{CH}_{4}$ dissociation on the three surfaces. In particular, we consider the influence of the choice of the exchange-correlation (XC) functional, the inclusion of long-range van der Waals dispersion forces, and the role of lateral interactions between adsorbates on the vibrational frequency of $\mathrm{CH}_{3}$ chemisorbed on various sites of the three surfaces mentioned above.

\section{Methodology}

\subsection{Experiments}

The molecular beam-surface science apparatus used here has been described in detail previously [45]. Briefly, the apparatus consists of a three-fold differentially pumped molecular beam source coupled to an ultra-high vacuum (UHV) chamber where reaction products adsorbed on the sample surface can be detected either by RAIRS or Auger Electron Spectroscopy (AES). Absolute sticking coefficient averaged over all surface sites can be determined by the King and Wells beam reflectivity method [29].

A continuous molecular beam was formed by skimming a jet expansion produced from a gas mixture of 1-3 bar stagnation pressure through a stainless steel nozzle. The translational energy of the molecular beam was controlled by seeding methane on He and by heating the nozzle $\left(\mathrm{T}_{\mathrm{N}}=300-850 \mathrm{~K}\right)$. The speed distribution of $\mathrm{CH}_{4}$ in the molecular beam was measured by a time-of-flight (TOF) method using a chopper wheel in combination with an on-axis quadrupole mass spectrometer [46].

The molecular beam entered the UHV chamber with a base pressure of $5 \times 10^{-11}$ mbar where it collided at normal incidence with the surface sample of $10 \mathrm{~mm}$ diameter. The three different single crystal surfaces used in the experiments shown in this study, $\operatorname{Pt}(111), \operatorname{Pt}(211)$ and $\operatorname{Pt}(110)-(1 \times 2)$, were obtained from Surface Preparation Labs and were cut within $0.1^{\circ}$ of the specified crystal plane. The samples were mounted on a liquid nitrogen cryostat using $0.4 \mathrm{~mm}$ diameter tungsten wires. Surface temperature was controlled in the range of 90-1200 K using nitrogen cooling and by resistive heating of the tungsten wires.

Models of the surface structure for the three different $\mathrm{Pt}$ samples are shown in Fig. 1. The $\operatorname{Pt}(211)$ surface consists of three-atom-wide (111) terraces and one-atom-high (100) steps. Unlike the $\operatorname{Pt}(111)$ and $\operatorname{Pt}(211)$, the $\operatorname{Pt}(110)$ surface is reconstructed and exhibits a $(1 \times 2)$ missing-row reconstruction that leads to a corrugated structure consisting of alternating ridges and valleys [47].

Surface cleaning between measurements was done by exposing the surfaces to $5 \times 10$ [8] mbar of $\mathrm{O}_{2}$ at a surface temperature of $700 \mathrm{~K}$ for $5 \mathrm{~min}$ followed by annealing at $\mathrm{T}_{\mathrm{S}}=1100 \mathrm{~K}$ for $2 \mathrm{~min}$. The surface cleanliness was confirmed using Auger Electron Spectroscopy (AES).

The methane dissociation products were detected by the RAIRS technique using an evacuated Fourier transform infrared (FTIR) spectrometer (Bruker Vertex V70) with an external InSb infrared detector.
Fig. 1 Models of the a $\operatorname{Pt}(111)$, b $\operatorname{Pt}(211)$, c $\operatorname{Pt}(110)-(1 \times 2)$ surfaces with its different surface sites

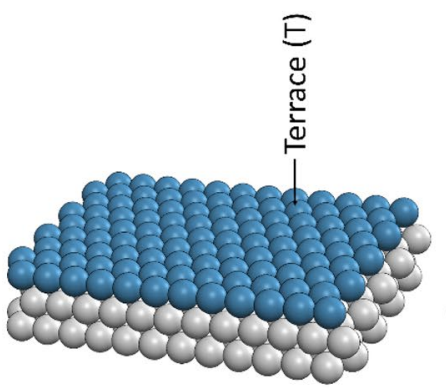

(a) $\operatorname{Pt}(111)$

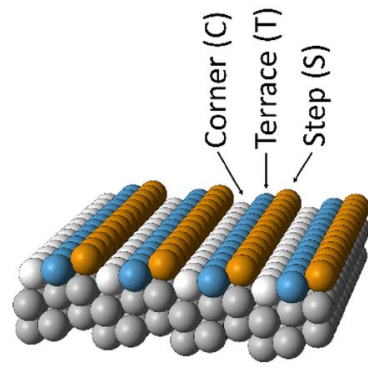

(b) $\operatorname{Pt}(211)$

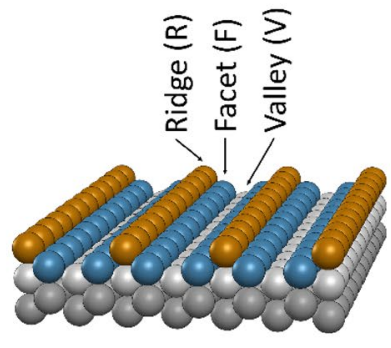

(c) $\operatorname{Pt}(110)-(1 \times 2)$ 
The incident dose D of methane molecules on the surface can be calculated from [48]:

$D=\frac{\Delta P S}{k_{B} T_{g} A} t$

where $\Delta P$ is the methane partial pressure rise in the UHV chamber when the molecular beam is introduced into the UHV chamber, and it is obtained from a calibrated QMS. $S$ is the effective pumping speed for methane in the UHV chamber, $k_{B}$ is the Boltzmann's constant, $T_{g}(\mathrm{~K})$ is the gas temperature to the $298 \mathrm{~K}, A$ is the molecular beam spot area on the surface determined by AES and $t$ is the deposition time. In order to express the dose in monolayers (ML), the surface atom density of the different surfaces has to be taken into account $\left(1.5 \times 10^{15} \mathrm{Pt}\right.$ atoms $/ \mathrm{cm}^{2}$ on $\mathrm{Pt}(111), 1.59 \times 10^{15}$ $\mathrm{Pt}$ atoms $/ \mathrm{cm}^{2}$ on $\mathrm{Pt}(211)$ and $1.84 \times 10^{15} \mathrm{Pt}$ atoms $/ \mathrm{cm}^{2}$ on $\operatorname{Pt}(110)-(1 \times 2))$.

\subsection{Theory}

DFT calculations have been performed using a plane-wave basis set and the projected augmented wave method [49] to describe the interaction of valence electrons with atomic cores, as implemented in the VASP code [50-55]. The number of valence electrons considered for the atomic species $\mathrm{H}$, of exposed Pt atoms of the three surfaces under study here, we adopt and extend the nomenclature used in Ref. [32] for $\operatorname{Pt}(211)$. Thus, we qualify the exposed atoms of $\operatorname{Pt}(211)$ as: step (S), terrace $(\mathrm{T})$, and corner $(\mathrm{C})$. In $\mathrm{Pt}(111)$, there are only $\mathrm{T}$ atoms exposed. For $\mathrm{Pt}(110)-(1 \times 2)$, the exposed atoms will be referred to as ridge $(\mathrm{R})$, facet $(\mathrm{F})$ and valley $(\mathrm{V})$, respectively. In Fig. 1, S and R, T and F, and $\mathrm{C}$ and $\mathrm{V}$ atoms are represented as orange, blue, and gray spheres respectively. Figure 2, shows the optimum adsorption geometries we have obtained for $\mathrm{CH}_{3}$ on $\mathrm{T}$ and $\mathrm{S}$ sties of $\mathrm{Pt}(211)$, on $\mathrm{F}$ and $\mathrm{R}$ sites of $\mathrm{Pt}(110)-(1 \times 2)$ and on $\mathrm{T}$ sites of $\mathrm{Pt}(111)$.

In order to investigate possible effects of long-range van der Waals interactions on the frequencies of $\mathrm{CH}_{3}$, we have also performed DFT calculations with the PBE-D3 method [57] and with the so-called optPBE-vdW XC functional [58].

We define adsorption energies of the single species $\mathrm{X}$ ( $\left.\mathrm{X}=\mathrm{CH}_{4}, \mathrm{CH}_{3}, \mathrm{H}\right)$, as:

$E_{a d s}[X]=E[X /$ surface $]-E[X]-E[$ surface $]$

where $\mathrm{E}[\mathrm{X} /$ surface], $\mathrm{E}[\mathrm{X}]$, and $\mathrm{E}$ [surface] are the total energies of the full system $X /$ surface, $X$ in vacuum, and the clean surface respectively. Note that more negative values of $\mathrm{E}_{\text {ads }}[\mathrm{X}]$ correspond to more stable adsorption. For $\mathrm{n} \mathrm{CH}_{3}$ groups $(\mathrm{n}=1,2)$ co-adsorbed with $\mathrm{m} \mathrm{H}$ atoms $(\mathrm{m}=0,1$, 2 ), we also use $\mathrm{E}_{\mathrm{ads}}\left[\mathrm{CH}_{3}\right]$ to denote the average adsorption energy, which we compute as follows:

$E_{\text {ads }}\left[\mathrm{CH}_{3}\right]=\left\{E\left[\left(n \mathrm{CH}_{3}+m H\right) /\right.\right.$ surface $]-n E\left[\mathrm{CH}_{3}\right]-m E[H]-E[$ surface $\left.]-m E_{\text {ads }}[H]\right\} / n$

$\mathrm{C}$ and $\mathrm{Pt}$ were 1, 4, and 10 respectively. We used a smearing of width $0.1 \mathrm{eV}$, and an energy cut-off of $450 \mathrm{eV}$. Most of the calculations have been performed with the PBE semilocal XC functional [56]. The Pt(111), Pt(211), and $\mathrm{Pt}(110)$ $(1 \times 2)$ surfaces have been modeled within the slab-supercell approach using $\mathrm{N}=5,7$, and 7 Pt layers, and supercells $3 \times 3$, $1 \times 3$, and $1 \times 3$ respectively. The k-point meshes used to sample the first Brillouin zone were $5 \times 5 \times 1$ for $\operatorname{Pt}(111)$ and $\operatorname{Pt}(211)$, and $7 \times 7 \times 1$ for $\operatorname{Pt}(110)-(1 \times 2)$. In all the geometry optimizations performed for adsorbate/surface systems, we kept the Pt atoms in the $\mathrm{N}_{\text {bot }}$ bottom layers fixed in their equilibrium positions obtained for the clean surface $\left(\mathrm{N}_{\text {bot }}=3\right.$ for $\operatorname{Pt}(111)$, and $\mathrm{N}_{\text {bot }}=4$ for $\operatorname{Pt}(211)$ and $\left.\operatorname{Pt}(110)-(1 \times 2)\right)$, and we allowed full relaxation of the coordinates of all the other Pt atoms and those of the adsorbates. Geometry optimizations to look for local minima and saddle points in the adsorbate/surface interaction potential were performed using the quasi-Newton, conjugate-gradient, and dimer methods of the VASP code by setting IBRION $=1,2$, and 44 respectively (see [55] and references therein).

As mentioned above, it is well known that methyl groups chemisorb on the top sites of various low-Miller-index Pt surfaces, i.e. with the $\mathrm{CH}_{3}$-surface bond directly involving a single Pt atom. For simplicity, to distinguish different types
The results presented here correspond to spin-restricted calculations except for the energies of $\mathrm{CH}_{3}$ and $\mathrm{H}$ in vacuum. The vibrational frequencies are computed within the harmonic approximation as the square root of the eigenvalues of the Hessian matrix corresponding to the total energy of the system as a function of the atomic coordinates. To evaluate the Hessian matrix elements, we use the finite differences method with two displacements per atomic coordinate of $\mathrm{CH}_{3}$ (one back and one forward) of $0.015 \AA$. A few test calculations considering 16 valence electrons for $\mathrm{Pt}$ atoms instead of 10 showed that the choice of the number of valence electrons of Pt barely affects the computed frequencies for $\mathrm{CH}_{3}$ (ads).

It might be argued that DFT plus the harmonic approximation might be not accurate enough to account for the measured $17 \mathrm{~cm}^{-1}$ frequency shift between $\mathrm{CH}_{3}$ (ads) on $\mathrm{Pt}(211)-\mathrm{S}$ and $\mathrm{Pt}(211)-\mathrm{T}$ sites. However, even though DFT calculations tend to predict frequencies too large compared to experiment, the difference in vibrational frequency between different adsorption sites are much better reproduced. For instance, using the methodology described above, we were able to reproduce properly (both in absolute value and sign) the $-17 \mathrm{~cm}^{-1}$ shift between the RAIRS peaks corresponding to the stretching frequency of $\mathrm{CO}$ on $\mathrm{Pt}(211)-\mathrm{S}$ and on $\mathrm{Pt}(211)-\mathrm{T}$ [43]. 

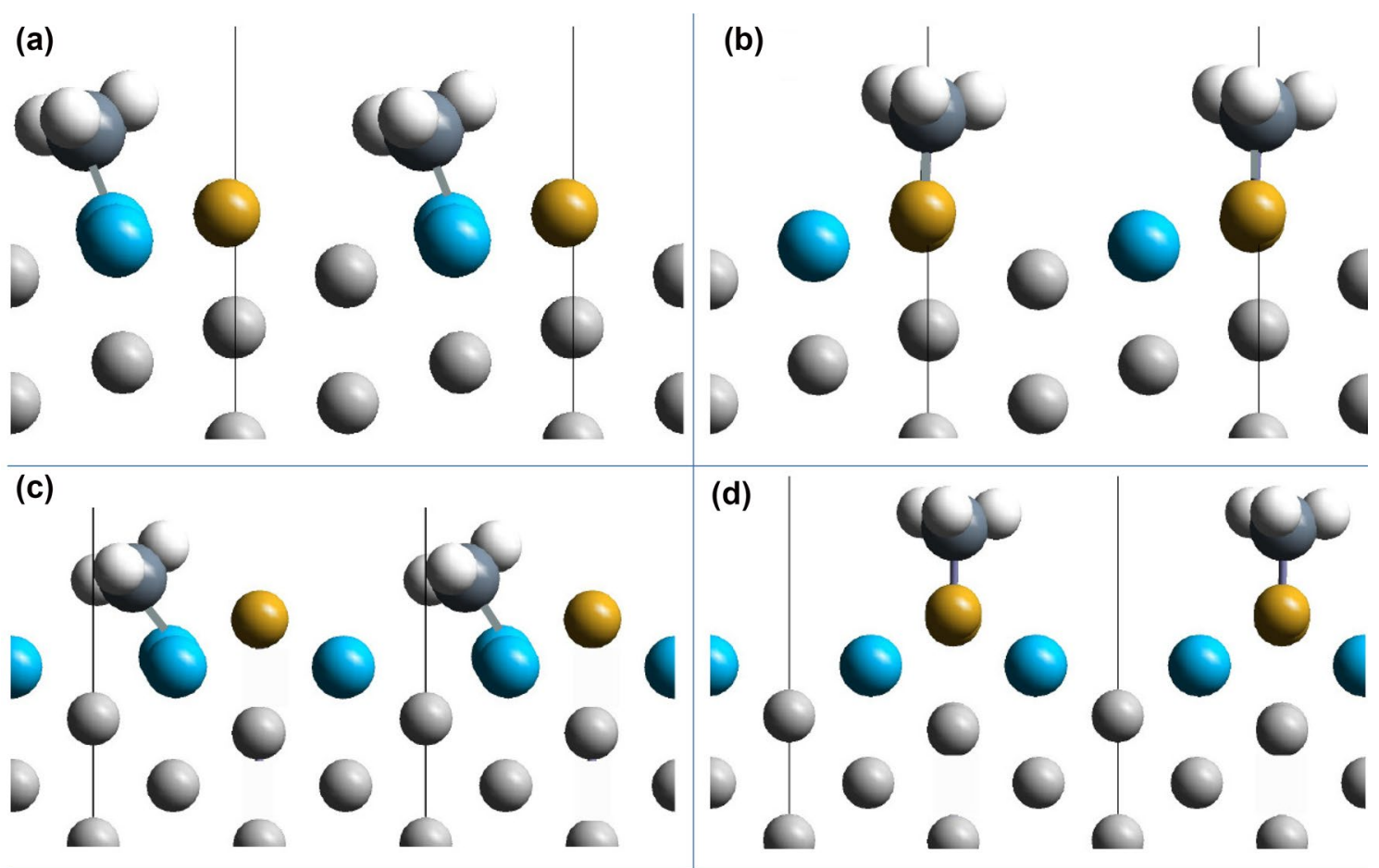

(e)

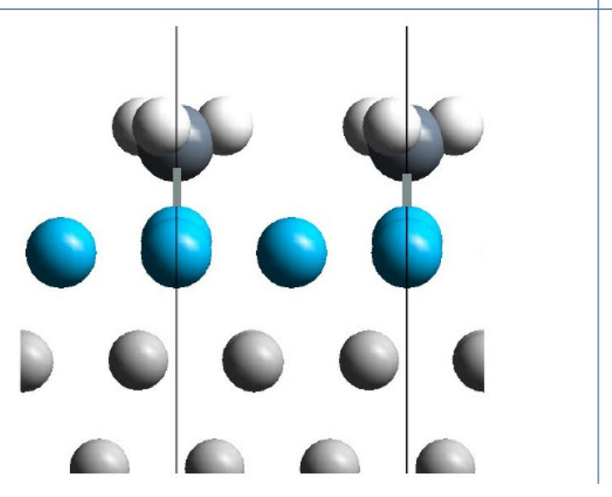

Fig. 2 Optimum DFT-PBE structure for $\mathrm{CH}_{3}$ chemisorption on $\mathrm{Pt}(211)-\mathrm{T}(\mathbf{a}), \operatorname{Pt}(211)-\mathrm{S}(\mathbf{b}), \operatorname{Pt}(110)-(1 \times 2)-\mathrm{F}(\mathbf{c}), \operatorname{Pt}(110)-(1 \times 2)-\mathrm{R}(\mathbf{d})$, and $\mathrm{Pt}(111)-\mathrm{T}(\mathbf{e}) . \mathrm{T}, \mathrm{S}$, and $\mathrm{C} \mathrm{Pt}$ atoms are represented in orange, blue, and gray respectively

\section{Results and Discussion}

\subsection{Experiments}

\subsubsection{RAIR Spectra: Surface-Site-Selective Detection of Chemisorbed Methyl Groups}

Figure 3 shows RAIR spectra following dissociative chemisorption of $\mathrm{CH}_{4}$ on $\mathrm{Pt}(111), \mathrm{Pt}(211)$, and $\mathrm{Pt}(110)-(1 \times 2)$. $\mathrm{On} \operatorname{Pt}(111)$ at low surface temperature, $\mathrm{CH}_{4}$ is known to dissociate directly on impact by cleaving a single $\mathrm{C}-\mathrm{H}$ bond resulting in chemisorbed $\mathrm{CH}_{3}$ (ads) and $\mathrm{H}(\mathrm{ads})[45,59,60]$. DFT calculations predict the dissociation to take place over the top site on $\mathrm{Pt}(111)$ with the $\mathrm{CH}_{3}$ (ads) product on the top site and $\mathrm{H}(\mathrm{ads})$ in a hollow site [61]. Temperature program reaction measurements showed that $\mathrm{CH}_{3}$ (ads) is stable up to $\mathrm{T}_{\mathrm{s}}=200 \mathrm{~K}$ [62] on the terrace sites of $\mathrm{Pt}(111)$. For $\mathrm{T}_{\mathrm{s}}>200 \mathrm{~K}$ dehydrogenation leads to $\mathrm{CH}$ (ads) adsorbed on the hollow sites [62-64]. Figure 3a shows the RAIRS signal for the symmetric $\mathrm{C}-\mathrm{H}$ stretch vibration of $\mathrm{CH}_{3}$ (ads) on $\operatorname{Pt}(111)$ with a single peak at $2881 \mathrm{~cm}^{-1}$.

Recently, we have demonstrated the ability of RAIRS to distinguish between $\mathrm{CH}_{3}$ adsorbed on the steps and terraces of $\operatorname{Pt}(211)$ [32]. Figure $3 \mathrm{~b}$ shows a spectrum taken after dissociation of $\mathrm{CH}_{4}$ on the $\mathrm{Pt}(211)$ with an incident translational energy of $65 \mathrm{~kJ} / \mathrm{mol}$. Comparison of the spectra taken following deposition under similar conditions on $\operatorname{Pt}(111)$ leads us to assign the RAIRS signals to $\mathrm{CH}_{3}(\mathrm{ads})$ on the step and terrace sites. The lack of a third peak, corresponding to $\mathrm{CH}_{3}$ (ads) on the corner sites, is consistent with a much 


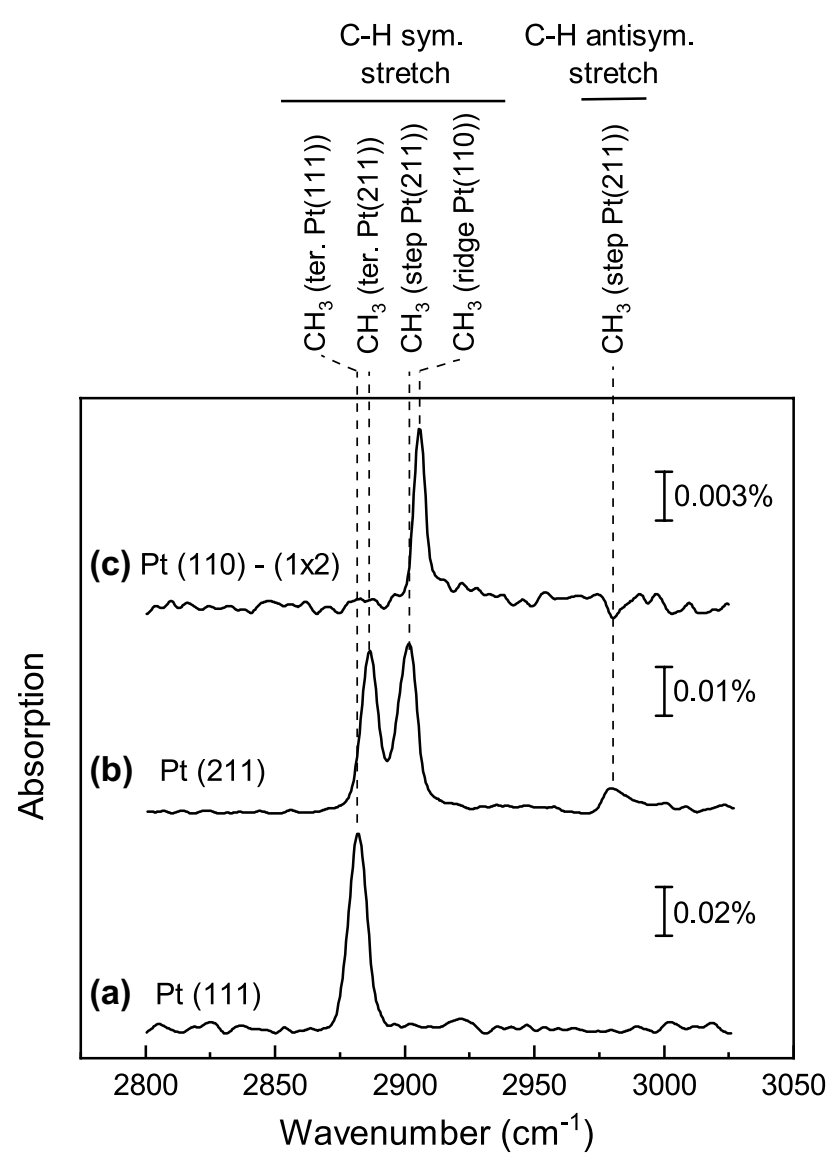

Fig. 3 RAIRS detection of $\mathrm{CH}_{3}$ (ads) adsorbed on a) $\mathrm{Pt}(111)$, b) $\mathrm{Pt}(211)$, and c) $\mathrm{Pt}(110)-(1 \times 2)$ at $\mathrm{T}_{\mathrm{S}}=120 \mathrm{~K} . \mathrm{CH}_{3}$ (ads) was generated by dissociative chemisorption of $\mathrm{CH}_{4}$ with incident kinetic energy in the range of $62-65 \mathrm{~kJ} / \mathrm{mol}$

higher barrier for dissociation on these sites, calculated by DFT as $183 \mathrm{~kJ} / \mathrm{mol}$ [32].

A confirmation of the peak assignments for $\mathrm{CH}_{3}$ (ads) on the step and terrace sites was obtained by passivating the step atoms of the surface with $\mathrm{CO}(\mathrm{ads})$. $\mathrm{CO}$ adsorption on platinum surfaces has been extensively studied using RAIRS and its vibrational frequency on step and terrace sites are well-known [43, 65-67]. Following the saturation of the steps with $\mathrm{CO}(\mathrm{ads})$, we exposed the $\mathrm{Pt}(211)$ surface to a $\mathrm{CH}_{4}$ molecular beam with $65 \mathrm{~kJ} / \mathrm{mol}$ incident translational energy. Only the RAIRS signal at $2886 \mathrm{~cm}^{-1}$ was observed, confirming our assigned to $\mathrm{CH}_{3}$ (ads) on the terrace sites. Figure 4 shows a comparison of the spectrum obtained after deposition of $\mathrm{CH}_{4}$ on the clean $\mathrm{Pt}(211)$ surface and the spectrum obtained at the same incident energy conditions on the $\operatorname{Pt}(211)$ where the steps were passivated by $\mathrm{CO}$ (ads). The observed vibrational frequencies are given with their assignments in Table 1.

In our most recent experiments, we extended the sitespecific detection capabilities of RAIRS to the missingrow reconstructed $\mathrm{Pt}(110)-(1 \times 2)$ surface. Previously [68],

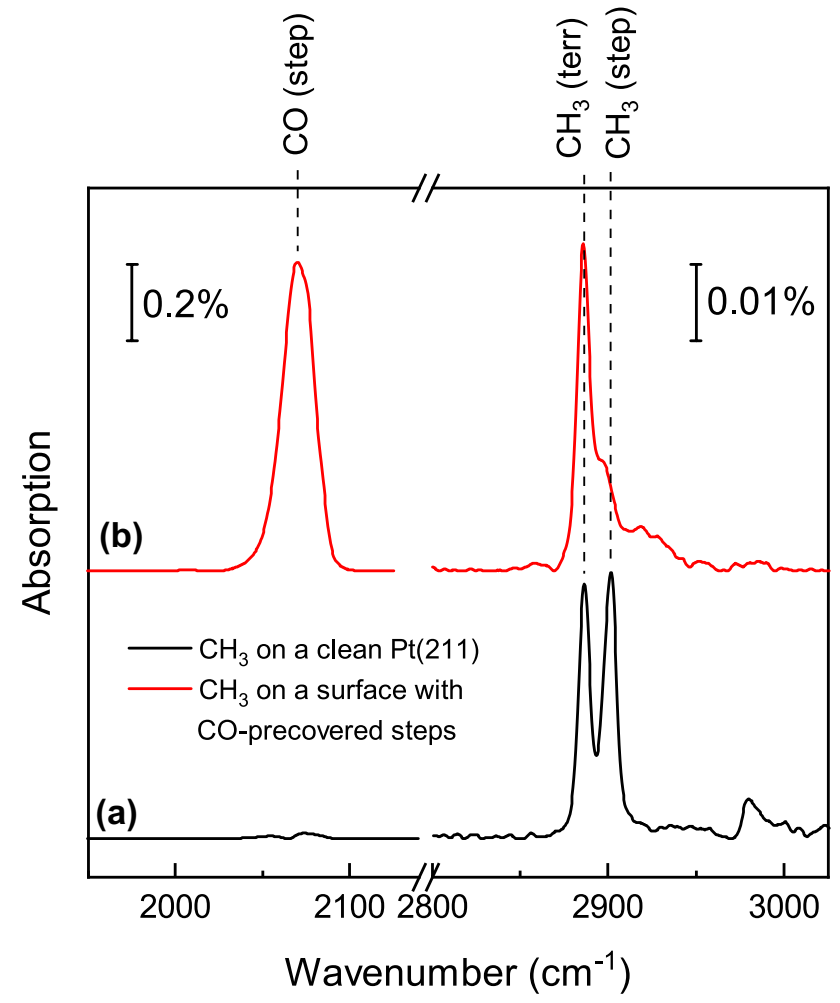

Fig. 4 RAIR spectra following 45 min deposition of a $3 \% \mathrm{CH}_{4}$ in He molecular beam at $E_{\text {trans }}=65 \mathrm{~kJ} / \mathrm{mol}$ at $T_{S}=150 \mathrm{~K}$ : a) on a clean $\operatorname{Pt}(211)$ surface, $b)$ on a $\operatorname{Pt}(211)$ surface with steps passivated with $\mathrm{CO}$ (ads). Note the difference in absorption scales for $\mathrm{CO}$ (ads) and $\mathrm{CH}_{3}$ (ads) as indicated in the figure

Table 1 Assignments of RAIRS peaks observed for nascent methyl products of $\mathrm{CH}_{4}$ dissociation on $\mathrm{Pt}(111), \mathrm{Pt}(211)$ and $\mathrm{Pt}(110)-(1 \times 2)$ at $\mathrm{T}_{\mathrm{S}}=150 \mathrm{~K}$

\begin{tabular}{llll}
\hline Surface & Site & $\begin{array}{l}\text { Frequency } \\
\left(\mathrm{cm}^{-1}\right)\end{array}$ & Mode assignment \\
\hline $\operatorname{Pt}(111)$ & Terraces & 2881 & Symmetric C-H stretch \\
$\operatorname{Pt}(211)$ & Terraces & 2886 & Symmetric C-H stretch \\
& Steps & 2903 & Symmetric C-H stretch \\
& & 2979 & Antisymmetric C-H stretch \\
$\operatorname{Pt}(110)-(1 \times 2)$ & Ridges & 2905 & Symmetric C-H stretch \\
\hline
\end{tabular}

Peak frequencies are taken from spectra in Fig. 3

we have measured the polar and azimuthal incident angle dependence for the dissociation probability of $\mathrm{CH}_{4}$ on $\mathrm{Pt}(110)-(1 \times 2)$ by AES and $\mathrm{K} \& \mathrm{~W}$ detection [68], which do not provide the site-selectivity of RAIRS. From the difference in the incident polar angle dependence of the sticking probability for incidence parallel and perpendicular to the missing rows, we concluded that the reactivity of $\mathrm{CH}_{4}$ on the ridges should be much higher than in the valleys. Our experiments using RAIRS detection reported here confirm and strengthen this conclusion. Figure $3 \mathrm{c}$ shows a RAIR 


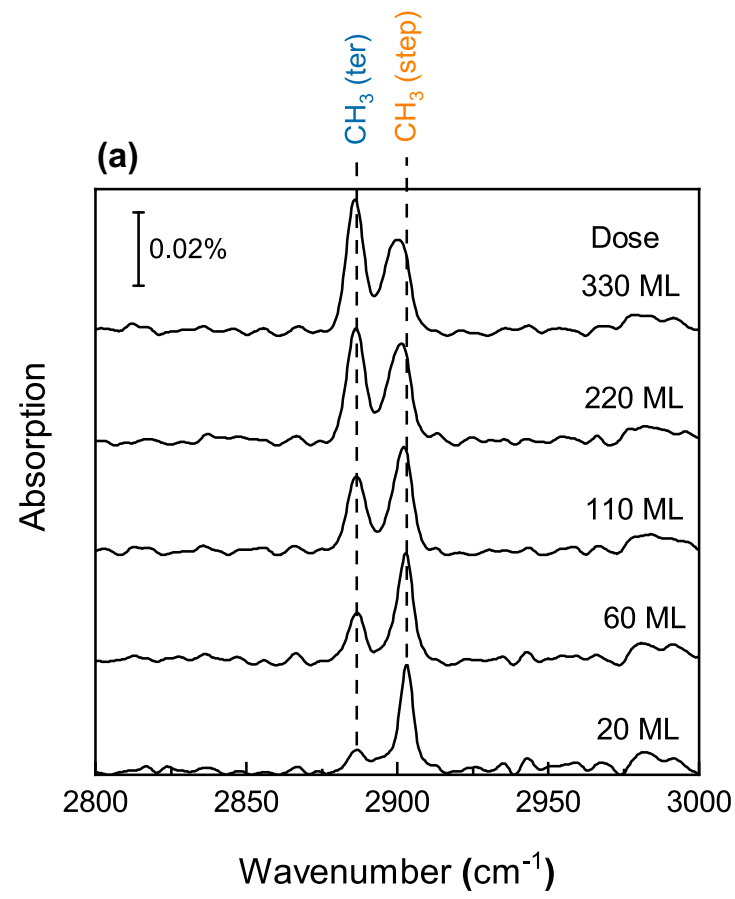

Fig. 5 a RAIR spectra taken during exposure of the $\operatorname{Pt}(211)$ surface at different incident doses of $\mathrm{CH}_{4}$ at $\mathrm{E}_{\text {trans }}=65 \mathrm{~kJ} / \mathrm{mol}$ and $\mathrm{T}_{\mathrm{S}}=120 \mathrm{~K}$. b Uptake curves for $\mathrm{CH}_{3}$ (ads) on the steps (orange) and on the terraces (blue) obtained integrating the area under the peaks for $\mathrm{CH}_{3}$ adsorbed

spectrum measured following a $30 \mathrm{~min}$ deposition of $\mathrm{CH}_{4}$ on the Pt(110)- $(1 \times 2)$ surface with an incident energy of $62 \mathrm{~kJ} /$ mol. We observe a single RAIRS peak in the $\mathrm{C}-\mathrm{H}$ stretch region indicating that $\mathrm{CH}_{3}$ (ads) occupies only a single site on the $\operatorname{Pt}(110)-(1 \times 2)$ surface. We assigned this peak at $2905 \mathrm{~cm}^{-1}$ to the symmetric stretch vibration of $\mathrm{CH}_{3}$ (ads) on the ridge atoms of $\mathrm{Pt}(110)-(1 \times 2)$ since we expect the ridge atoms to be the most reactive ones on this surface [68]. The assignment to $\mathrm{CH}_{3}(\mathrm{ads})$ on the ridge atoms of $\mathrm{Pt}(110)-(1 \times 2)$ is consistent with the assignment of the $2903 \mathrm{~cm}^{-1}$ peak to $\mathrm{CH}_{3}$ (ads) on the step atoms of $\mathrm{Pt}(211)$, since the two sites have the same coordination number of 7 . Previous studies for $\mathrm{CO}$ adsorption have shown that the singleton frequency of $\mathrm{CO}$ (ads) on $\mathrm{Pt}$ is a linear function of the coordination number of the substrate atom where the $\mathrm{CO}$ molecule is adsorbed [69].

Since RAIRS does not interfere with the chemisorption process, it can be used to monitor uptake curves of the methane dissociation product $\mathrm{CH}_{3}$ (ads) during the molecular beam deposition. Figure 5a shows the evolution of the RAIR spectra with increasing incident dose for a $3 \% \mathrm{CH}_{4}$ in $\mathrm{He}$ molecular beam at $65 \mathrm{~kJ} / \mathrm{mol}$ incident energy on the $\operatorname{Pt}(211)$ surface. Each spectrum is an average of 1024 scans with $4 \mathrm{~cm}^{-1}$ resolution for an acquisition time of about $2.5 \mathrm{~min}$. The absorption peak at $2903 \mathrm{~cm}^{-1}$ assigned to $\mathrm{CH}_{3}(\mathrm{ads})$ on the step sites appears first, followed by the terrace peak at

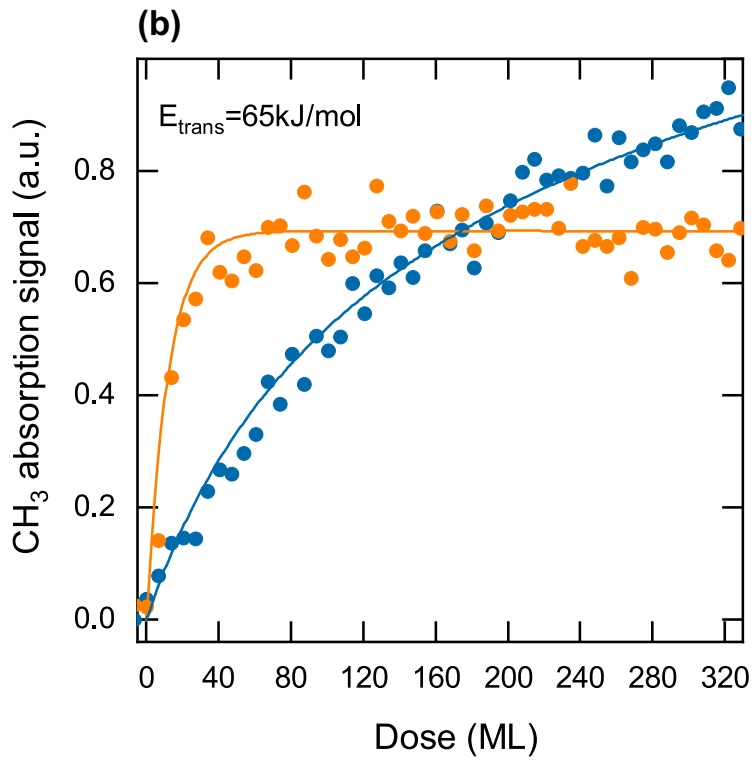

on the step and terrace sites. The solid line corresponds to the fit to the experimental data points obtained using a Langmuir type uptake model [79]

$2886 \mathrm{~cm}^{-1}$. With increasing $\mathrm{CH}_{3}$ (ads) coverage, we observe a $2-3 \mathrm{~cm}^{-1}$ red-shift of the step peak accompanied by some broadening while the frequency and linewidth of the terrace peak appears to be independent of coverage. The spectral changes observed for the step peak are likely due to a tilting of the methyl species on the steps when the terrace sites start to be populated by $\mathrm{CH}_{3}$ (ads).

Figure $5 \mathrm{~b}$ shows the integrated peak areas for the $\mathrm{CH}_{3}$ (ads) on step and terrace sites, obtained by fitting the sum of two Gaussians to the measured RAIRS signal as a function of incident dose. We observed a much faster $\mathrm{CH}_{3}$ (ads) uptake on the steps than on the terraces, indicating a higher reactivity on the lower coordinated step sites. This is consistent with calculated barrier heights for the dissociation of $\mathrm{CH}_{4}$ on steps and terraces of $\mathrm{Pt}(211)$ and in agreement with our assignment of the RAIRS signals for $\mathrm{CH}_{3}$ (ads) on step and terraces sites.

In order to test if $\mathrm{CH}_{3}$ (ads) diffusion occurs at $\mathrm{T}_{\mathrm{s}}=120 \mathrm{~K}$ on $\mathrm{Pt}(211)$ as proposed by Papp et al. [31] for $\operatorname{Pt}(533)$ and $\mathrm{Pt}(322)$ [31], $\mathrm{Pt}(211)$ was exposed to a beam of $\mathrm{CH}_{4}$ with $\mathrm{E}_{\text {trans }}=56 \mathrm{~kJ} / \mathrm{mol}$. Figure 6 shows that at low incident energy, $\mathrm{CH}_{3}$ (ads) uptake occurs selectively on the steps, confirming the lower barrier for methane dissociation on the steps compared to the terraces. After 15 min deposition at $\mathrm{E}_{\text {trans }}=56 \mathrm{~kJ} / \mathrm{mol}$ and with the steps now saturated with $\mathrm{CH}_{3}$ (ads), the molecular beam deposition was stopped 


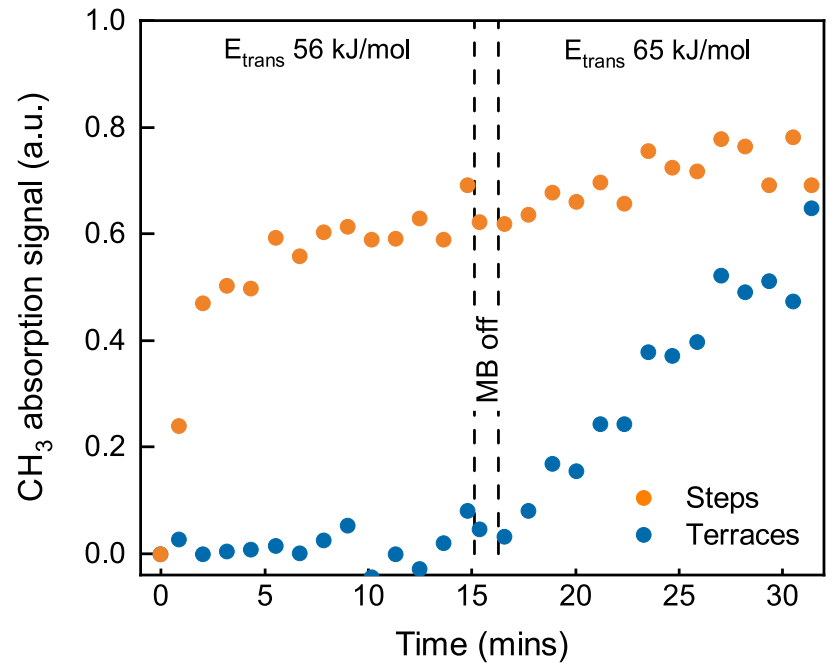

Fig. 6 RAIRS uptake curves for methane dissociation on the terraces (blue) and steps (orange) of $\operatorname{Pt}(211)$ for $\mathrm{T}_{\mathrm{S}}=120 \mathrm{~K}$ [80]. During the first $15 \mathrm{~min}$, the incident translation energy of $\mathrm{CH}_{4}$ was $\mathrm{E}_{\text {trans }}=56 \mathrm{~kJ} /$ mol and $\mathrm{CH}_{3}$ (ads) is detected only on the steps. For $\mathrm{t}>16 \mathrm{~min}, \mathrm{E}_{\text {trans }}$ was raised to $65 \mathrm{~kJ} / \mathrm{mol}$, leading to $\mathrm{CH}_{3}$ (ads) uptake also on the terrace sites

for $2 \mathrm{~min}$. If dissociation also occurred on the terraces at $\mathrm{E}_{\text {trans }}=56 \mathrm{~kJ} / \mathrm{mol}$ and rapid diffusion caused the $\mathrm{CH}_{3}$ (ads) to move to the step sites as proposed by Papp et al., we would expect to detect an increase in the terrace peak height at $\mathrm{E}_{\text {trans }}=56 \mathrm{~kJ} / \mathrm{mol}$ once the steps are saturated. This is not observed in Fig. 6. The terrace peak only starts to grow when the incident energy is raised to $E_{\text {trans }}=65 \mathrm{~kJ} / \mathrm{mol}$. Therefore, we can exclude surface diffusion of $\mathrm{CH}_{3}(\mathrm{ads})$ at $\mathrm{T}_{\mathrm{s}}=120 \mathrm{~K}$ which is consistent with a calculated barrier of $64 \mathrm{~kJ} / \mathrm{mol}$ [32] by DFT for methyl diffusion from the terraces to the steps.

\subsubsection{Surface-Site-Specific Methane Sticking Coefficients}

The slope of the RAIRS detected uptake curve shown in Fig. $5 \mathrm{~b}$ is proportional to the coverage dependent sticking coefficient $S(\theta)$. In order to determine $S(\theta)$ from the uptake, we calibrated the RAIRS absorption signal in terms of adsorbate coverage on each specific surface site.

Using site-specific RAIRS detection, we can decompose the total sticking coefficient, measured for example by a $\mathrm{K} \& \mathrm{~W}$ experiment into the contributions from the different surface sites present on the surface. For example for $\operatorname{Pt}(211)$ we can write:

$S_{0}($ total $)=\rho_{s} \cdot S_{0}($ step $)+\rho_{t} \cdot S_{0}($ terrace $)+\rho_{c} \cdot S_{0}($ corner $)$

where $\mathrm{S}_{0}$ (step), $\mathrm{S}_{0}$ (terrace), and $\mathrm{S}_{0}$ (corner) are the surfacesite-specific sticking coefficients for step, terrace and corner sites each multiplied by the relative density $\rho_{\mathrm{i}}$ of the specific

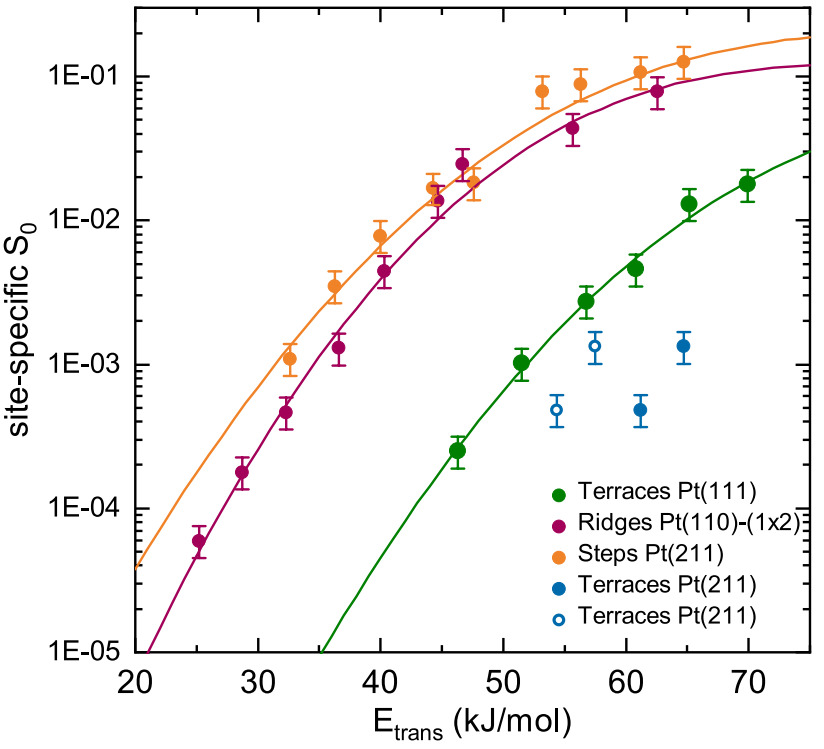

Fig. 7 Site-specific initial sticking coefficient $S_{0}$ vs. incident translational energy $\left(\mathrm{E}_{\text {trans }}\right)$ : terrace sites of $\operatorname{Pt}(111)\left(\mathrm{T}_{\mathrm{S}}=150 \mathrm{~K}\right.$, green) [80], the ridges of the $\operatorname{Pt}(110)-(1 \times 2)$ surface $\left(\mathrm{T}_{\mathrm{S}}=120 \mathrm{~K}\right.$, red $)$, and the steps (orange) and terraces (blue) of the $\operatorname{Pt}(211)$ surface $\left(\mathrm{T}_{\mathrm{S}}=120 \mathrm{~K}\right)$. The solid symbols are $S_{0}$ as a function $E_{\text {trans }}$ measured normal to the macroscopic surfaces. The open symbol $S_{0}$ vs. $E_{\text {trans }}$ normal to the (111) terrace of the $\operatorname{Pt}(211)$ surface which are tilted by $19.5^{\circ}$ relative to the 211 crystal plane. The solid lines corresponds to the fit to the experimental data points obtained using Eq. (5)

surface site $i$. The contribution of the different sites to the total sticking coefficient $\mathrm{S}_{0}$ depends on the incident translational energy $\mathrm{E}_{\text {trans }}$ due to the site-dependent dissociation barriers. For example, at low $\mathrm{E}_{\mathrm{t}}$, the total sticking coefficient $\mathrm{S}_{0}$ is given exclusively by the contribution of the steps $\rho_{\mathrm{s}} \cdot \mathrm{S}_{0}($ step), since these are the sites with the lowest dissociation barrier, while with increasing $\mathrm{E}_{\text {trans }}$ the contribution of the terrace sites increases.

The definition of site-specific initial sticking coefficients allows for comparison of the specific reactivity on different surface sites. In order to determine the surface-site-specific sticking coefficients from the site-specific RAIRS uptake curves, we need to know the incident dose on each of the different surface sites. To do so, the total incident dose on the surface calculated from Eq. (1) is converted to the fractional dose on each site. On the $\mathrm{Pt}(211)$ surface, the fractional dose on each site (step, terrace and corner) is assumed to be $1 / 3$ of the total incident dose since the surface layer consists of these three types of atoms in equal proportion. On the $\mathrm{Pt}(110)$ $(1 \times 2)$ surface, the incident dose on the ridge atoms is assumed to be $1 / 4$ of the total incident dose.

Figure 7 shows a comparison of the site-specific $S_{0}$ values for the different sites on three different Pt surfaces as a function of incident translational energy. To better visualize the 
trend in $\mathrm{S}_{0}$ as a function of incident energy, we fitted so-called S-shaped reactivity curves [2] to the data points:

$S_{0}=\frac{A}{2}\left[1+\operatorname{erf}\left(\frac{E_{\text {trans }}-E_{0}}{W}\right)\right]$

where $A$ is the asymptotic value of $\mathrm{S}_{0}$ at high incident energy, $\mathrm{E}_{0}$ is the average activation barrier height and $\mathrm{W}$ is the width of the distribution of barrier heights assumed to be Gaussian.

For all the incident energies studied, we observed the highest reactivity for the lowest coordinated step and ridge sites. This is consistent with the reactivity ordering predicted by the DFT-PBE results described below. The DFTPBE activation energy barrier we have obtained for dissociation on the $\mathrm{Pt}(211)-\mathrm{T}$ sites is higher than on $\mathrm{Pt}(211)-\mathrm{S}$ sites, in agreement with results reported in a previous study [32]. Still, the present difference between both activation energies is smaller than the one of Ref. [32]: $38 \mathrm{~kJ} / \mathrm{mol} \mathrm{vs.}$ $55 \mathrm{~kJ} / \mathrm{mol}$.

We find the $\operatorname{Pt}(110)-(1 \times 2)$ ridge sites to have a slightly lower sticking coefficient than the step sites on $\operatorname{Pt}(211)$ while both have the same coordination number $\mathrm{CN}=7$. This is in qualitative agreement with the theoretical results presented here and previously reported $[32,39]$. By fitting the measured kinetic energy dependence of the site-specific sticking coefficients $\mathrm{S}_{0}$ both for the steps and the ridges using Eq. (5) with a constant asymptote A and width $\mathrm{W}$ for the distribution of barrier heights, we obtain an average activation barrier height $\mathrm{E}_{0} \sim 3 \mathrm{~kJ} / \mathrm{mol}$ higher for the ridges than for the steps. This difference in the average barrier height obtained experimentally is smaller than the difference in the minimum barriers for dissociation on the steps and ridges calculated using DFT. Our PBE results predict a minimum energy barrier on ridge sites higher than on the steps by $29 \mathrm{~kJ} / \mathrm{mol}$. This value is slightly larger than the one reported by B. Jackson and co-workers (also using the PBE functional but without accounting for surface relaxation during the calculation of the transition state geometry): $22 \mathrm{~kJ} / \mathrm{mol}$ higher on the ridges than on the steps [32,39]. Interestingly, using a specific reaction parameter (SRP) XC functional, Chadwick et al. [70] predicted a barrier on the ridges higher than on the steps by only $10 \mathrm{~kJ} / \mathrm{mol}$ which is closer to the experimental value observed here.

Recently, we reported a comparison between the experimental sticking coefficients for $\operatorname{Pt}(110)-(1 \times 2)$ measured at $\mathrm{T}_{\mathrm{S}}=650 \mathrm{~K}$ using the $\mathrm{K} \& \mathrm{~W}$ method and the ones predicted by ab initio quasi-classical trajectory calculations using the latter SRP XC functional [70]. Both agree very well at high incident energies but disagree for incident energies lower than $110 \mathrm{~kJ} / \mathrm{mol}$. Good agreement was found between the calculated and measured reactivities at low energies as long as some contribution to the dissociation from molecules trapped on the surface was included.

This trapping mediated channel on $\operatorname{Pt}(110)-(1 \times 2)$ could explain why the measured reactivities are larger than predicted by theory without including this trapping channel. However, the existence of trapping mediated dissociation could not be confirmed by our experiments. The lifetime of physisorbed $\mathrm{CH}_{4}$ on $\operatorname{Pt}(110)-(1 \times 2)$ at $\mathrm{T}_{\mathrm{S}}=120 \mathrm{~K}$ is around $32 \mathrm{~ms}$ [70]. Taking into account the flux of incident molecules on the surface, we expect to have less than $1 \%$ of a $\mathrm{ML}$ of $\mathrm{CH}_{4}$ on the surface, which is below our limits of detection.

Another interesting feature shown in Fig. 7 is a difference in the sticking coefficient between the terraces of the flat $\operatorname{Pt}(111)$ surface and the terraces of $\operatorname{Pt}(211)$ which were assumed to be identical in previous studies [28, 31]. Although both sites have the same coordination number $(\mathrm{CN}=9)$, the $\mathrm{Pt}(111)$ terrace sites are more reactive. A possible reason for this discrepancy is the different normal incident energies onto the terraces of $\mathrm{Pt}(111)$ and $\mathrm{Pt}(211)$ surface. Since the (111) microfacets of the $\mathrm{Pt}(211)$ surface are tilted with respect to the macroscopic (211) surface plane by $19.5^{\circ}$, the incident normal energy onto the 211 terraces is lower by a factor of $\cos [2]\left(19.5^{\circ}\right)=0.63 \mathrm{com}$ pared to the 111 terraces for a molecular beam incident normal the macroscopic surface plane. Using this correction for the local normal incident energy, we obtained the open symbols shown in Fig. 7, which are in better agreement with the $\mathrm{S}_{0}$ on the terraces of $\mathrm{Pt}(111)$. The remaining horizontal offset between the data points for $\operatorname{Pt}(111)$ and the corrected $\mathrm{S}_{0}$ values for the terraces of $\mathrm{Pt}(211)$ is approximately $5 \mathrm{~kJ} / \mathrm{mol}$, close to the calculated difference between the DFT-PBE energy barriers for $\mathrm{Pt}(211)-\mathrm{T}$ and $\mathrm{Pt}(111)-\mathrm{T}$ sites of only $3 \mathrm{~kJ} / \mathrm{mol}$.

These results demonstrate that the coordination number of the surface atoms where absorption takes place is not the only factor which determines the site-specific reactivity and that the local environment surrounding the surface site also plays a role. Calle-Vallejo et al. [71] proposed the use of the generalized coordination number $(\mathrm{CN})$ that takes into account the coordination number of the nearest neighbor atoms. Therefore, this number can take into account the main difference between the (111) terrace of the stepped and the flat surfaces as well as the difference between the steps on $\operatorname{Pt}(211)$ and the ridges of $\mathrm{Pt}(110)$ $(1 \times 2)$. However, the generalized coordination number is higher on the terraces of the $\operatorname{Pt}(111)$ surface $(\mathrm{CN}=7.5)$ than on the terraces of the $\operatorname{Pt}(211)(\mathrm{CN}=7.33)$, and it is also higher on the steps of $\mathrm{Pt}(211)(\mathrm{CN}=5.5)$ than on the ridges of the $\mathrm{Pt}(110)-(1 \times 2)(\mathrm{CN}=5.16)$. Therefore, a higher reactivity would be expected on the terrace sites of the $\operatorname{Pt}(211)$ than on the terrace sites of $\operatorname{Pt}(111)$, and 
Table 2 DFT-PBE results for the minimum dissociation barrier height for $\mathrm{CH}_{4}$ chemisorption, $\mathrm{E}_{\mathrm{b}}$, adsorption energy of $\mathrm{CH}_{3}$, $\mathrm{E}_{\text {ads }}\left[\mathrm{CH}_{3}\right]$, frequency of the symmetric stretching mode of $\mathrm{CH}_{3}$, and

\begin{tabular}{llllllll}
\hline Surface-site & $\mathrm{E}_{\mathrm{b}}(\mathrm{kJ} / \mathrm{mol})$ & $\begin{array}{l}\mathrm{E}_{\mathrm{ads}}\left[\mathrm{CH}_{3}\right] \\
(\mathrm{kJ} / \mathrm{mol})\end{array}$ & $v_{\text {sym }}\left(\mathrm{cm}^{-1}\right)$ & $<\mathrm{d}_{\mathrm{C}-\mathrm{H}}>(\AA)$ & $\mathrm{d}_{\mathrm{C}-\mathrm{Pt} 1}(\AA)$ & $\mathrm{d}_{\mathrm{H}-\mathrm{Pt} 1}(\AA)$ & $\mathrm{d}_{\mathrm{H}-\mathrm{P} t 2}(\AA)$ \\
\hline $\operatorname{Pt}(111)-\mathrm{T}$ & 64 & -198 & 2973 & 1.097 & 2.067 & $2.625-2.626-2.625$ & $3.211-3.225-3.241$ \\
$\operatorname{Pt}(211)-\mathrm{T}$ & 67 & -207 & 2977 & 1.097 & 2.060 & $2.608-2.614-2.623$ & $3.213-3.205-3.223$ \\
$\operatorname{Pt}(211)-\mathrm{S}$ & 30 & -218 & 2969 & 1.098 & 2.056 & $2.595-2.627-2.630$ & $3.152-3.423-3.665$ \\
$\operatorname{Pt}(110)-\mathrm{F}$ & - & -195 & 2962 & 1.098 & 2.065 & $2.639-2.615-2.609$ & $3.364-3.220-3.362$ \\
$\operatorname{Pt}(110)-\mathrm{R}$ & 59 & -193 & 2964 & 1.098 & 2.054 & $2.628-2.605-2.610$ & $3.666-3.406-3.144$ \\
\hline
\end{tabular}

some relevant interatomic distances in the optimum chemisorption geometry for the methyl group a higher reactivity would be expected on the ridges of $\operatorname{Pt}(110)-(1 \times 2)$ than on the steps of $\operatorname{Pt}(211)$ opposite to the experimental results observed here. We suggest that the slightly higher reactivity of $\mathrm{Pt}(111)-\mathrm{T}$ sites compared with $\mathrm{Pt}(211)-\mathrm{T}$ ones, might be due to the $2 \%$ compression of $\mathrm{T} \mathrm{Pt}$ atoms of $\mathrm{Pt}(211)$, provoked by the relaxation of the stepped surface (see below).

\subsection{Theory}

Energetic and geometrical aspects of $\mathrm{CH}_{4}, \mathrm{CH}_{3}$, and $\mathrm{H}$ adsorption on $\operatorname{Pt}(111), \operatorname{Pt}(211)$, and $\operatorname{Pt}(110)-(1 \times 2)$, including the energy of transition states for $\mathrm{CH}_{4}$ dissociation, have been studied previously by DFT calculations by a number of authors [21, 32, 35-42, 72, 73]. However, the use of different theoretical models complicates a direct comparison of the results for various systems among each other, and with our experiments. Moreover, vibrational frequencies of the chemisorbed methyl groups and their surface site dependence have not been predicted by theory to the best of our knowledge. Therefore, here we report results of new DFT calculations. With the DFT settings mentioned above in Section III.b., the minimum dissociation barriers for $\mathrm{CH}_{4}$ dissociation on $\mathrm{Pt}(111)-\mathrm{T}, \mathrm{Pt}(211)-\mathrm{T}, \mathrm{Pt}(211)-\mathrm{S}$, and $\mathrm{Pt}(110)-(1 \times 2)-\mathrm{R}$ are: $64 \mathrm{~kJ} / \mathrm{mol}, 67 \mathrm{~kJ} / \mathrm{mol}, 30 \mathrm{~kJ} / \mathrm{mol}$, and $59 \mathrm{~kJ} / \mathrm{mol}$ respectively (see Table 2 ). We have considered only $\mathrm{T}$ and $\mathrm{S}$ sites for $\mathrm{Pt}(211)$ and $\mathrm{R}$ ones for $\mathrm{Pt}(110)-(1 \times 2)$ because previous theoretical studies $[32,74]$ have estimated the corresponding activation energy barriers on other sites, to be too high to be accessible in the experimental conditions considered in this work. The $\mathrm{E}_{\mathrm{b}}$ values reported here slightly differ from those reported previously in the literature due to several reasons that include the use of a rigid surface model by other authors, different XC functionals, number of Pt layers to model the surface, size of the supercells, k-point meshes, and energy cut-offs [21, 32, 37, 39, 40, 57]. Still, as far as the relative reactivity is concerned (taking the $\mathrm{E}_{\mathrm{b}}$ as the prescriptor), our results agree well with them, and predict the following ordering for reactivity: $\operatorname{Pt}(211)$ $\mathrm{S}>\mathrm{Pt}(110)-(1 \times 2)-\mathrm{R}>\mathrm{Pt}(111)-\mathrm{T}>\mathrm{Pt}(211)-\mathrm{T}$. Interestingly, the $\mathrm{CH}_{4}$ activation energy on $\mathrm{Pt}(211)-\mathrm{S}$ sites is significantly smaller than on the other three sites for which the dissociation barriers are close to each other. Since the coordination numbers of $\mathrm{S} P t$ atoms of $\operatorname{Pt}(211)$ and $\operatorname{Pt}(110)-(1 \times 2)$ are both $\mathrm{CN}=7$ and the dissociation barrier height in the former case is calculated to be $29 \mathrm{~kJ} / \mathrm{mol}$ smaller than in the latter, it is clear that other ingredients (not only the coordination number) do play an important role for reactivity, in line with our experiments (see above). In addition, both $\mathrm{Pt}(111)-\mathrm{T}$ and $\mathrm{Pt}(211)$-T have $\mathrm{CN}=9$ and the barrier on the latter Pt atom is calculated to be larger than on the former by $3 \mathrm{~kJ} / \mathrm{mol}$. This relatively small difference between barriers on the two $\mathrm{T}$ sites is likely due to a compressive strain effect. The average distance between the $\operatorname{Pt}(211)-\mathrm{T}$ atoms and their nearest neighbor (NN) exposed Pt's is $2 \%$ smaller than the NN distance between Pt atoms in the flat Pt(111) surface due to the stepped (211) surface relaxation. Such a compressive strain produces a downshift of the d-band center for metal atoms with more than half-filling of the d-band like Pt which in turn (according to the d-band model [75-77]) provokes a decrease of reactivity.

In Table 2, we report minimum dissociation barrier heights for $\mathrm{CH}_{4}$, adsorption energies for $\mathrm{CH}_{3}$, interatomic distances relevant for the optimum adsorption geometries, and the vibrational frequency of the symmetric $\mathrm{C}-\mathrm{H}$ stretch mode $v_{\text {sym }}$ for $\mathrm{CH}_{3}$ chemisorbed on $\operatorname{Pt}(111), \operatorname{Pt}(211)$, and $\mathrm{Pt}(110)-(1 \times 2)$. On $\mathrm{Pt}(211)-\mathrm{S}, \mid \mathrm{E}_{\mathrm{ads}}\left[\mathrm{CH}_{3}\right] \mathrm{l}$ is larger than on $\mathrm{Pt}(211)-\mathrm{T}$ by $\sim 10 \mathrm{~kJ} / \mathrm{mol}$ consistent with the higher reactivity for lower coordinated step atoms. It is interesting to note that the reactivity ordering deduced from the barrier heights is not respected if we take the adsorption energy of $\mathrm{CH}_{3}$ as a probe of reactivity. In fact, on $\mathrm{Pt}(110)-(1 \times 2)-\mathrm{S}, \mid \mathrm{E}_{\text {ads }}\left[\mathrm{CH}_{3}\right]$ is the smallest (weakest $\mathrm{CH}_{3}$-surface bond), whereas the activation energy for $\mathrm{CH}_{4}$ dissociation on this site is the second smallest one among all the sites we have investigated. Still, all the values of $\mathrm{E}_{\mathrm{ads}}\left[\mathrm{CH}_{3}\right]$ shown in Table 2 are close to each other, differences being $\leq 10 \%$.

For $\mathrm{CH}_{3}$ chemisorbed on $\mathrm{T}$ sites of $\mathrm{Pt}(111)$ and $\mathrm{Pt}(211)$, the $\nu_{\text {sym }}$ values are close to each other: $2973 \mathrm{~cm}^{-1}$ and $2977 \mathrm{~cm}^{-1}$. This further validates the assignment of the RAIRS peak of $\mathrm{CH}_{3}$ on $\mathrm{T}$ sites of $\mathrm{Pt}(211)$ described above. On the other hand, the frequencies computed for $\mathrm{CH}_{3}$ 
Table 3 Influence of the choice of the electronic exchangecorrelation functional and van der Waals interaction on the $\mathrm{CH}_{4}$ physisorption energy, $\mathrm{CH}_{3}$ adsorption energy, and frequency of the symmetric stretching mode of the chemisorbed $\mathrm{CH}_{3}$ on $\mathrm{Pt}(211)$

\begin{tabular}{llll}
\hline & $\operatorname{Pt}(111)(2 \times \sqrt{ } 3)$ supercell & $\operatorname{Pt}(211)$ & \\
\cline { 4 - 4 } & Terrace $(\mathrm{T})$ & Terrace $(\mathrm{T})$ & Step $(\mathrm{S})$ \\
\hline $\mathrm{E}_{\mathrm{ads}}\left[\mathrm{CH}_{4}\right](\mathrm{kJ} / \mathrm{mol})$ & & & \\
$\mathrm{PBE}$ & -3 & -2 & -3 \\
$\mathrm{PBE}-\mathrm{D} 3$ & -27 & -30 & -23 \\
optPBE-vdW & -25 & -22 & -18 \\
$\mathrm{E}_{\text {ads }}\left[\mathrm{CH}_{3}\right](\mathrm{kJ} / \mathrm{mol})$ and $\mathrm{d}_{\mathrm{C}-\mathrm{Pt} 1}(\AA)$ & & -218 and 2.056 \\
$\mathrm{PBE}$ & -198 and 2.067 & -207 and 2.060 & -243 and 2.054 \\
PBE-D3 & -230 and 2.067 & -243 and 2.057 & -238 and 2.062 \\
optPBE-vdW & -226 and 2.074 & -236 and 2.067 & 2969 \\
$\nu_{\text {sym }}\left(\mathrm{cm}{ }^{-1}\right)$ & & & 2961 \\
PBE & 2973 & 2977 & 2940 \\
PBE-D3 & 2967 & 2969 & \\
optPBE-vdW & 2945 & 2949 & \\
\hline
\end{tabular}

chemisorbed on $\mathrm{S}$ sites are also close to each other: $2969 \mathrm{~cm}^{-1}$ and $2964 \mathrm{~cm}^{-1}$ but smaller than the frequencies corresponding to $\mathrm{T}$ sites, the latter finding being in contrast with experiments. Interestingly, the frequencies predicted for $\mathrm{CH}_{3} / \mathrm{Pt}(110)-(1 \times 2)-\mathrm{V}$ and $\mathrm{CH}_{3} / \mathrm{Pt}(110)-(1 \times 2)-\mathrm{R}$ are rather close $\left(2962 \mathrm{~cm}^{-1}\right.$ vs. $\left.2964 \mathrm{~cm}^{-1}\right)$ which might entail a difficulty for the use of RAIRS to perform site-selective reactivity measurements even in conditions under which dissociation on both $\mathrm{T}$ and $\mathrm{S} \mathrm{Pt}$ atoms of $\mathrm{Pt}(110)-(1 \times 2)$ could be possible. However, the frequency difference between $\mathrm{CH}_{3} / \mathrm{Pt}(211)-\mathrm{S}$ and $\mathrm{CH}_{3} / \mathrm{Pt}(211)-\mathrm{T}$ measured by RAIRS is $\Delta \nu=\nu_{\text {sym }}^{\mathrm{S}}-\nu_{\text {sym }}^{\mathrm{T}}=+17 \mathrm{~cm}^{-1}$, while our DFT-PBE results predict a shift in the opposite direction with $\Delta \nu=-8 \mathrm{~cm}^{-1}$.

In order to elucidate the origin of this discrepancy, we compare the adsorption geometries of $\mathrm{CH}_{3}$ on $\mathrm{S}$ and $\mathrm{T} \mathrm{Pt}$ atoms in Table 2, where we report the values of the $\mathrm{C}-\mathrm{Pt}$ and $\mathrm{C}-\mathrm{H}$ bond lengths $\left(\mathrm{d}_{\mathrm{C}-\mathrm{Pt}}\right.$, and $\left.\mathrm{d}_{\mathrm{C}-\mathrm{H}}\right)$, as well the distance between each $\mathrm{H}$ atom of the methyl group and its nearest Pt neighbor (NN), and next nearest Pt neighbor $(\mathrm{NNN}): \mathrm{d}_{\mathrm{H}-\mathrm{Pt} 1}$ and $\mathrm{d}_{\mathrm{H}-\mathrm{Pt} 2}$ respectively. In all cases, the $\mathrm{Pt}$ atom that is $\mathrm{NN}$ to the $\mathrm{H}$ atoms is the binding site of the $\mathrm{CH}_{3}$ group. We find similar values for $\mathrm{d}_{\mathrm{C}-\mathrm{Pt}}, \mathrm{d}_{\mathrm{C}-\mathrm{H}}$, and $\mathrm{d}_{\mathrm{H}-\mathrm{Pt} 1}$ for all adsorption geometries. However, there are differences between the values of $\mathrm{d}_{\mathrm{H}-\mathrm{Pt} 2}$, for $\mathrm{CH}_{3}$ adsorption on a $\mathrm{T}$ or $\mathrm{S} \mathrm{Pt}$ atom. In particular, whereas on a $\mathrm{T}$ Pt atom, the three values of $\mathrm{d}_{\mathrm{H}-\mathrm{Pt} 2}$ are all $\sim 3.2 \AA$, on a $\mathrm{S}$ Pt atom the three values of $\mathrm{d}_{\mathrm{H}-\mathrm{Pt} 2}$ are $\sim 3.2 \AA$, $3.4 \AA$, and $3.6 \AA$. Therefore, when $\mathrm{CH}_{3}$ is adsorbed on a $\mathrm{T}$ Pt atom the $\mathrm{C}-\mathrm{H}$ bonds are closer and can interact slightly stronger with the Pt surface (see Fig. 2). This might cause a stronger softening of the $\mathrm{C}-\mathrm{H}$ bonds and consequently, a frequency of $\mathrm{CH}_{3}$ bound to a $\mathrm{T} \mathrm{Pt}$ atom, might become smaller than for $\mathrm{CH}_{3}$ on a S Pt atom as observed experimentally [32]. In fact, this is the effect that produces for $\mathrm{CH}_{3}$ adsorbed on a fcc-hollow site of $\mathrm{Pt}(111)$, a frequency $\sim 200 \mathrm{~cm}^{-1}$ smaller than on top, despite the smaller binding energy of $\mathrm{CH}_{3}$ in the former site [36]. However, our DFT-PBE results for the vibrational frequencies do not confirm this hypothesis which could be due to the large $\mathrm{d}_{\mathrm{H}-\mathrm{Pt} 2}$ values and the wellknown failure of the PBE functional to describe of longrange dispersion forces.

In order to investigate the possible effect of long-range van der Waals interactions on the vibrational frequencies of $\mathrm{CH}_{3}$ on $\mathrm{S}$ and $\mathrm{T}$ Pt atoms, we have also performed calculations using the PBE-D3 method [57], and with the optPBEvdW XC functional [56]. As indicated in Table 3, these calculations for $\operatorname{Pt}(111)$ have been performed for a $2 \times \sqrt{ } 3$ supercell. We previously verified that the choice of functional affects neither the adsorption energies nor the vibrational frequencies. As expected, the adsorption energies for the physisorption of $\mathrm{CH}_{4}$ (due to van der Waals interactions) obtained with PBE-D3 and optPBE-vdW are significantly larger than for PBE since the latter largely underestimates the depth of physisorption wells. PBE-D3 predicts physisorption energies larger than optPBE-vdW, both being in reasonable agreement with the estimated desorption energy extracted from temperature programmed desorption (TPD) results [78]. Interestingly, both calculations that incorporate $\mathrm{vdW}$ interactions predict a much smaller difference in adsorption energy for $\mathrm{CH}_{3}$ on $\mathrm{S}$ and $\mathrm{T}$ sites of $\mathrm{Pt}(211)$ than $\mathrm{PBE}$. This is consistent with the long-range dispersion forces contributing to the interaction of $\mathrm{C}-\mathrm{H}$ bonds with $\mathrm{Pt}$ atoms for $\mathrm{CH}_{3}$ in $\mathrm{T}$ sites more than for $\mathrm{S}$ sites. However, the frequencies reported in Table 3 show that this does not entail a significant change in the value of $\Delta v=\nu_{\text {sym }}^{\mathrm{S}}-v_{\text {sym }}^{\mathrm{T}}$ obtained with PBE. The predicted value by DFT for $\nu_{\text {sym }}$ for $\mathrm{CH}_{3}$ chemisorbed on $\mathrm{S}$ sites is, for all the methods we have used, $\sim 8-9 \mathrm{~cm}^{-1}$ smaller than on $\mathrm{T}$ sites which is at odds with experiment. 
Table 4 Lateral interaction between methyl groups chemisorbed on $\operatorname{Pt}(211)$

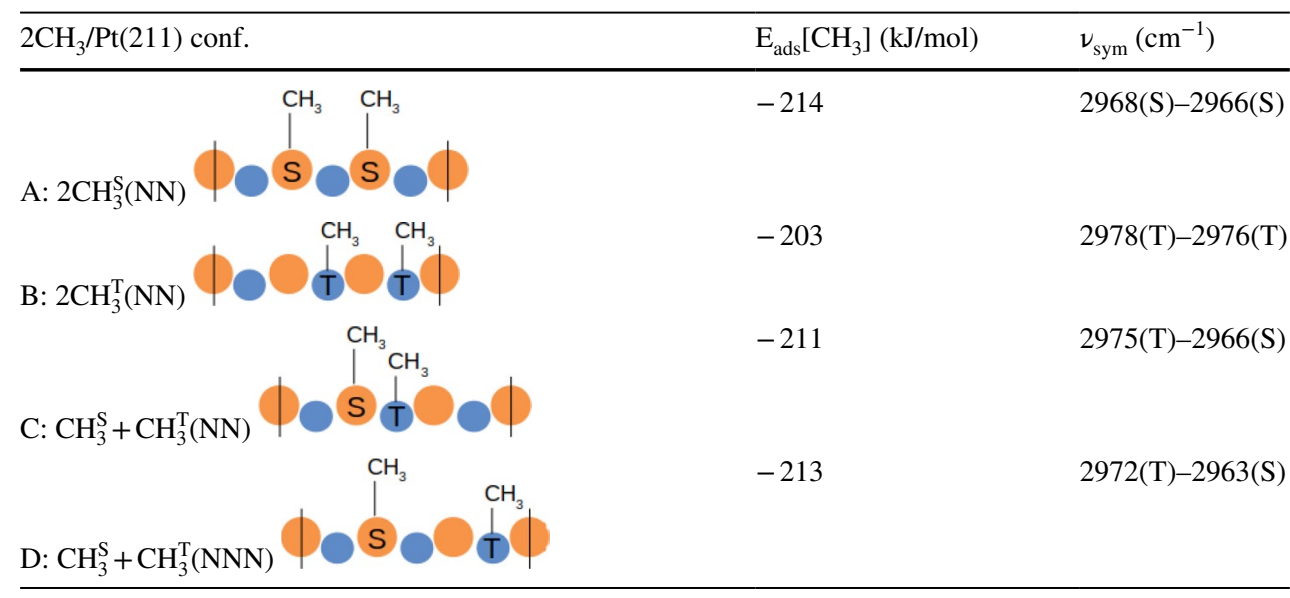

In the schematic representation of the configurations considered (side view of the $1 \times 3$ cell), $\mathrm{T}$ and $\mathrm{S} \mathrm{Pt}$ atoms are represented in orange and blue respectively. For simplicity $\mathrm{C} \mathrm{Pt}$ atoms are not included in the scheme
In view of this discrepancy with experiments, we have also investigated the effect of co-adsorbed species. Since RAIRS experiments are performed at a low surface temperature $(120-150 \mathrm{~K})$, well below the values for desorption of hydrogen atoms (forming $\mathrm{H}_{2}$ ) and full decomposition of $\mathrm{CH}_{3}$, it is useful to investigate how the presence of co-adsorbed $\mathrm{CH}_{3}$ (ads) and $\mathrm{H}(\mathrm{ads})$ affects the vibrational frequency of $\mathrm{CH}_{3}$ (ads). In Table 4, we show the average adsorption energy per methyl group, $\mathrm{E}_{\text {ads }}\left[\mathrm{CH}_{3}\right]$, when two $\mathrm{CH}_{3}$ groups are adsorbed simultaneously within the $1 \times 3$ supercell, making the coverage twice the value considered above. We have considered four different situations: (A) two $\mathrm{CH}_{3}$ adsorbed on $\mathrm{S} \mathrm{Pt}$ atoms $\mathrm{NN}$ with respect to each other, (B) two $\mathrm{CH}_{3}$ adsorbed on $\mathrm{T} \mathrm{Pt}$ atoms $\mathrm{NN}$ with respect to each other, (C) two $\mathrm{CH}_{3}$, one on a $\mathrm{S} \mathrm{Pt}$ atom and the other on a $\mathrm{T} \mathrm{Pt}$ atom, and NN with respect to each other, and (D) two $\mathrm{CH}_{3}$, one on a S Pt atom and the other on a $\mathrm{T}$ Pt atom, and NNN with respect to each other. The average adsorption energies show that the lateral interactions are rather weak, e.g. between $\sim 4$ and $5 \mathrm{~kJ} / \mathrm{mol}$ per molecule for two $\mathrm{CH}_{3}$ adsorbed on equivalent ( $\mathrm{T}$ or $\mathrm{S}$ ) $\mathrm{Pt}$ atoms that are $\mathrm{NN}$ to each other, and $\sim 0-2 \mathrm{~kJ} / \mathrm{mol}$ for two $\mathrm{CH}_{3}$ adsorbed on non-equivalent NN Pt atoms. This weak lateral interaction could in principle allow two or more methyl groups to stay adsorbed close to each other entailing some change of the position and shape of the RAIRS peaks for high enough doses of methane on the surface. However, for all the structures considered, the frequency of $\mathrm{CH}_{3}$ on a $\mathrm{T}(\mathrm{S}) \mathrm{Pt}$ atom remains between 2963 and $2968 \mathrm{~cm}^{-1}\left(2972\right.$ and $\left.2978 \mathrm{~cm}^{-1}\right)$. Thus, the $\mathrm{CH}_{3}$ frequency is only slightly affected by the presence of other methyl groups adsorbed nearby. Thus, our DFT results are in line with the relatively minor effect of co-adsorbed methyl groups on the RAIRS frequencies of $\mathrm{CH}_{3}$ (ads) on $\mathrm{T}$ and $\mathrm{S}$ sites for $\mathrm{Pt}(211)$.
In order to also consider the effect of co-adsorbed $\mathrm{H}$ atoms, we have computed the adsorption energy of $\mathrm{CH}_{3}$ and its vibrational frequency, in presence of one and two co-adsorbed $\mathrm{H}$ atoms in five different configurations (see Table 5). This requires the search of possible adsorption sites for a single $\mathrm{H}$ atom on $\mathrm{Pt}(211)$. We have found that $\mathrm{H}$ atoms prefer adsorption in a bridge configuration between two NN S Pt atoms, and the corresponding value of $\mathrm{E}_{\mathrm{ads}}[\mathrm{H}]$ is $-278 \mathrm{~kJ} / \mathrm{mol}$. This optimum adsorption geometry and its $E_{\text {ads }}$ value are both in good agreement with the results of previous DFT investigations for $\mathrm{H} / \mathrm{Pt}(211)$ [73]. From the results of Table 5, it is clear that the presence of coadsorbed $\mathrm{H}$ atoms affects the adsorption of $\mathrm{CH}_{3}$ more strongly than the presence of other $\mathrm{CH}_{3}$ groups (compare with Table 4). This is the case in particular for configurations in which both the $\mathrm{CH}_{3}$ group and a $\mathrm{H}$ co-adsorbed atom are bound to the same surface $\mathrm{Pt}$ atom. Comparing the $E_{\text {ads }}$ values of configurations $E$ and $F$ with the $-218 \mathrm{~kJ} /$ mol value obtained without $\mathrm{H}$ atoms co-adsorbed (see Table 2) we can see that shearing a Pt atom between $\mathrm{CH}_{3}$ and $\mathrm{H}$ (as in configuration $\mathrm{F}$ ) has an energy cost of $19 \mathrm{~kJ} /$ mol. In contrast, the presence of one $\mathrm{H}$ atom bound to $\mathrm{Pt}$ atoms that are $\mathrm{NN}$ of the Pt one where $\mathrm{CH}_{3}$ is bound (configuration E), slightly stabilizes chemisorption of $\mathrm{CH}_{3}$ by $4 \mathrm{~kJ} / \mathrm{mol}$ likely due to the lattice relaxation induced by the presence of $\mathrm{H}$. In any case, the presence of only one coadsorbed $\mathrm{H}$ atom does not affect the frequency of $\mathrm{CH}_{3}$, the frequencies obtained for configurations $\mathrm{E}$ and $\mathrm{F}$ being both the same $\left(2967 \mathrm{~cm}^{-1}\right)$ and very close to the one obtained without H, i.e. $2969 \mathrm{~cm}^{-1}\left(\mathrm{Pt}(211)-\mathrm{S}\right.$ in Table 2). The $\mathrm{E}_{\mathrm{ads}}$ values obtained with two co-adsorbed $\mathrm{H}$ atoms (configurations $\mathrm{G}$ and $\mathrm{H}$ in Table 5) follow the same tendency. Adding an extra $\mathrm{H}$ atom "far" from $\mathrm{CH}_{3}$ to configuration $\mathrm{F}$ (see configuration $\mathrm{G}$ ) provokes a slight stabilization of $\mathrm{CH}_{3}$ chemisorption whereas adding other $\mathrm{H}$ atom near $\mathrm{CH}_{3}$ 
Table $5 \mathrm{E}_{\text {ads }}\left[\mathrm{CH}_{3}\right]$ with co-adsorbed $\mathrm{H}$ atoms on $\mathrm{Pt}(211)$

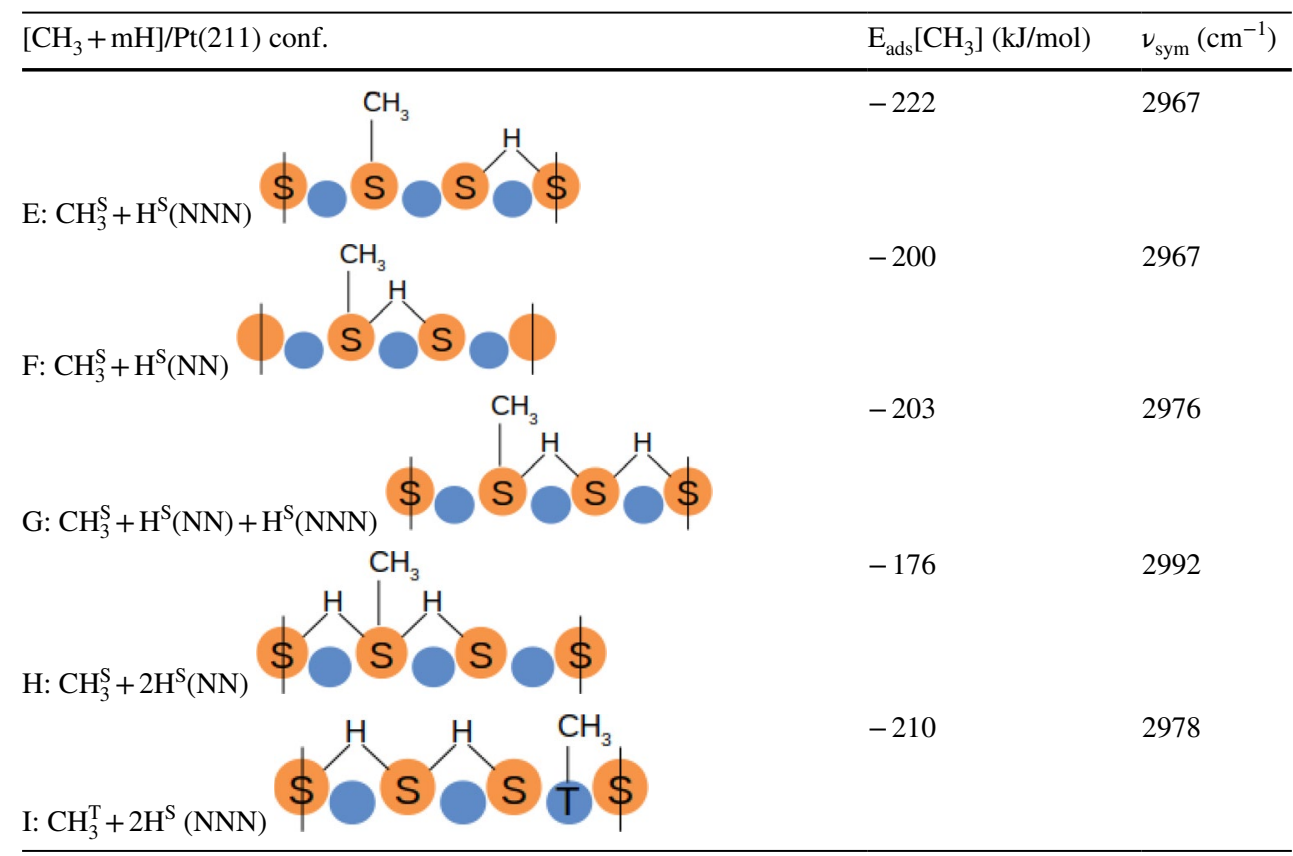

In the schematic representation of the configurations considered (side view of $1 \times 3$ cell), $\mathrm{T}$ and $\mathrm{S}$ Pt atoms are represented in orange and blue respectively. For simplicity $\mathrm{C} \mathrm{Pt}$ atoms are not included in the scheme (configuration $\mathrm{H}$ ) entails an extra energy cost of $-176 \mathrm{~kJ} /$ $\mathrm{mol}-(200 \mathrm{~kJ} / \mathrm{mol})=24 \mathrm{~kJ} / \mathrm{mol}$. This clearly shows that $\mathrm{H}$ atoms prefer to occupy bridge sites [in the step of $\mathrm{Pt}(211)]$ without sharing any $\mathrm{Pt}$ atom with $\mathrm{CH}_{3}$. Interestingly, the presence of an increasing number of $\mathrm{H}$ atoms decorating the step near $\mathrm{CH}_{3}$, provokes an increase of the frequency of $\mathrm{CH}_{3}$ chemisorbed on $\mathrm{Pt}(211)-\mathrm{S}$. However, due to the previous energetic considerations, it is not likely that frequency of $\mathrm{CH}_{3}$ on $\mathrm{Pt}(211)$-S larger than for $\mathrm{Pt}(211)$-T obtained experimentally, could be due to the presence of co-adsorbed $\mathrm{H}$ atoms since at low surface coverages, $\mathrm{H}$ atoms will be able to diffuse along the step to stay far away from $\mathrm{CH}_{3}$ (in configurations with significantly lower energies) where the effect on the $\mathrm{CH}_{3}$ frequency is negligible. This is also in line with the negligible effect of coverage on the $\mathrm{CH}_{3}$ frequencies observed experimentally. Finally, it is interesting to note in Table 5, that among the three configurations we have considered with two co-adsorbed $\mathrm{H}$ atoms $(\mathrm{G}, \mathrm{H}$, and I), the most stable one is that with the two $\mathrm{H}$ atoms chemisorbed in the step and $\mathrm{CH}_{3}$ chemisorbed on a $\mathrm{T}$ Pt atom: i.e. configuration I. This means that in the competition for step sites, $\mathrm{H}$ atoms win over $\mathrm{CH}_{3}$ and so, at relatively large coverages when there is no enough free $\mathrm{S} P t$ atoms, the $\mathrm{H}$ atoms are the ones that will occupy step sites pushing the $\mathrm{CH}_{3}$ groups to stay chemisorbed in T sites. However, the coverages for which such methyl displacement by $\mathrm{H}$ atoms is likely to take place is much larger than the highest coverage attained in our RAIRS experiments. To summarize the results of our analysis of coverage effects, we have found that for the low and moderate coverages involved in the
RAIRS experiments, the presence of neither $\mathrm{CH}_{3}$ nor $\mathrm{H}$ atoms are likely to significantly affect the frequencies of $\mathrm{CH}_{3}$ chemisorbed on $\mathrm{Pt}(211)-\mathrm{S}$ and $\mathrm{Pt}(211)-\mathrm{T}$ sites in line with experiments.

\section{Summary and Conclusions}

We report a combined experimental/theoretical investigation of methane dissociation on terrace $(\mathrm{T})$, step $(\mathrm{S})$, and ridge (R) sites of the $\operatorname{Pt}(111), \operatorname{Pt}(211)$, and $\operatorname{Pt}(110)-(1 \times 2)$ surfaces. Reflection Absorption Infrared absorption spectroscopy (RAIRS) is used for the surface site specific detection of chemisorbed methyl species on terrace, step and ridge atoms and to measure surface site specific methyl uptake curves. The uptake curves are used to calculate site specific sticking coefficients of $\mathrm{CH}_{4}$ on the different surface sites of these three surfaces. For each surface, we observe evidence for a direct chemisorption mechanism and the absence of $\mathrm{CH}_{3}$ (ads) diffusion from the terraces to the step sites on $\mathrm{Pt}(211)$ at $\mathrm{T}_{\mathrm{s}}<150 \mathrm{~K}$. The experimental sticking coefficients for different surface sites are in agreement with calculated dissociation barrier heights for methane dissociation by density functional theory (DFT) which predicts the lowest dissociation barrier for the step sites on $\mathrm{Pt}(211)$, followed by the ridge sites on $\operatorname{Pt}(110)-(1 \times 2)$, the terrace sites of $\operatorname{Pt}(111)$ and finally the terraces sites on $\operatorname{Pt}(211)$. DFT results confirm that the weak or absent dependence of the frequency and shape of the RAIRS peaks of $\mathrm{CH}_{3}$ (ads) are due to a weak interaction between methyl groups even when chemisorbed 
on top of neighbouring Pt atoms. In addition, the moderate coverages produced experimentally prevent the frequency upshift that might result from (energetically unfavored) moieties involving two $\mathrm{H}$ atoms and a methyl group bound all to the same Pt atom. Our DFT results predict RAIRS frequencies for $\mathrm{CH}_{3}$ (ads) on step and terrace sites opposite to what is observed experimentally on $\operatorname{Pt}(211)$. This discrepancy indicates that either DFT is not able to predict the correct RAIRS frequencies, or that the species adsorbed on the steps and terraces product of the dissociation are different. Further investigation is needed to resolve this disagreement between experiment and theory.

Acknowledgements This work was supported by the Consejo National de Investigationes Cientificas Técnicas (CONICET) and Ministerio de Educación, Cultura, Ciencia y Tecnología (ME) of Argentina and the Swiss National Science Foundation under the Argentinian-Swiss Joint Research Program (ASJRP) Project Nr. IZSAZ2-173328 as well as the ANPCyT Project PICT No. 2750 (ME-Argentina), and the UNR project PID ING534. M.E.T and H.F.B acknowledge computer time provided by CCT-Rosario Computational Center, and Centro de Simulación Computacional para Aplicaciones Tecnológicas (CSC), members of the High Performance Computing National System (SNCAD, ME-Argentina).

\section{References}

1. Chorkendorff I, Niemantsverdriet JW (2003) Concepts of modern catalysis and kinetics. Wiley-VCH, Weinheim

2. Juurlink LBF, Killelea DR, Utz AL (2009) Prog Surf Sci 84:69

3. Utz AL (2009) Curr Opin Solid State Mater Sci 13:4

4. Chadwick H, Beck RD (2017) Annu Rev Phys Chem 68:39

5. Chadwick H, Beck RD (2016) Chem Soc Rev 45:3576

6. Rettner CT, Pfnür HE, Auerbach DJ (1985) Phys Rev Lett 54:2716

7. Rettner CT, Pfnür HE, Auerbach DJ (1986) J Chem Phys 84:4163

8. Juurlink L, McCabe P, Smith R, DiCologero C, Utz AL (1999) Phys Rev Lett 83:868

9. Hundt PM, Jiang B, van Reijzen ME, Guo H, Beck RD (2014) Science 344:504

10. Bisson R, Dang TT, Sacchi M, Beck RD (2008) J Chem Phys 129:081103

11. Beck RD, Maroni P, Papageorgopoulos DC, Dang TT, Schmid MP, Rizzo TR (2003) Science 302:98

12. Smith RR, Killelea DR, DelSesto DF, Utz AL (2004) Science 304:992

13. Bisson R, Sacchi M, Dang TT, Yoder B, Maroni P, Beck RD (2007) J Phys Chem 111:12679

14. Bisson R, Sacchi M, Beck RD (2010) Phys Rev B 82:121404

15. Donald SB, Harrison I (2012) Phys Chem Chem Phys 14:1784

16. DeWitt KM, Valadez L, Abbott HL, Kolasinski KW, Harrison I (2006) J Phys Chem B 110:6705

17. Abbott HL, Bukoski A, Harrison I (2004) J Chem Phys 121:3792

18. Lozano A, Shen XJ, Moiraghi R, Dong W, Busnengo HF (2015) Surf Sci 640:25

19. Guo H, Jackson B (2015) J Phys Chem C 119:14769

20. Jiang B, Guo H (2013) J Phys Chem C 117:16127

21. Migliorini D, Chadwick H, Nattino F, Gutiérrez-González A, Dombrowski E, High EA, Guo H, Utz AL, Jackson B, Beck RD, Kroes GJ (2017) J Phys Chem Lett 8:4177

22. Nattino F, Migliorini D, Bonfanti M, Kroes GJ (2016) J Chem Phys 144:044702
23. Kroes GJ (2015) J Phys Chem Lett 6:4106

24. Sabbe MK, Reyniers MF, Reuter K (2012) Catal. Sci Technol 2:2010

25. Vattuone L, Savio L, Rocca M (2008) Surf Sci Rep 63:101

26. Libuda J, Freund HJ (2005) Surf Sci Rep 57:157

27. Juurlink L (2018) J Phys: Condens Matter 30:090301

28. Gee AT, Hayden BE, Mormiche C, Kleyn AW, Riedmüller B (2003) J Chem Phys 118:3334

29. King DA, Wells MG (1972) Surf Sci 29:454

30. Badan C, Koper MTM, Juurlink LBF (2015) J Phys Chem C 119:1355

31. Papp C, Tränkenschuh B, Streber R, Fuhrmann T, Denecke R, Steinrück HP (2007) J Phys Chem C 111:2177

32. Chadwick H, Guo H, Gutiérrez-González A, Menzel JP, Jackson B, Beck RD (2018) J Chem Phys 148:014701

33. Jackson B, Nave S (2011) J Chem Phys 135:114701

34. Nave S, Tiwari AK, Jackson B (2014) J Phys Chem A 118:9615

35. Papoian G, Nørskov JK, Hoffmann R (2000) J Am Chem Soc 122:4129

36. Michaelides A, Hu P (2001) J Chem Phys 114:2523

37. Petersen MA, Jenkins SJ, King DA (2004) J Phys Chem B 108:5909

38. Ford DC, Xu L, Mavrikakis M (2005) Surf Sci 587:159

39. Nave S, Tiwari AK, Jackson B (2010) J Chem Phys 132:054705

40. Chen Y, Vlachos DG (2010) J Phys Chem C 114:4973

41. Viñes F, Lykhach Y, Staudt T, Lorenz MPA, Papp C, Steinrück HP, Libuda J, Neyman KM, Görling A (2010) Chem A Eur J 16:6530

42. Qi Q, Wang X, Chen L, Li B (2013) Appl Surf Sci 284:784

43. Mukerji RJ, Bolina AS, Brown WA (2003) Surf Sci 527:198

44. Gutiérrez-González A, Crim FF, Beck RD (2018) J Chem Phys 149:074701

45. Chen L, Ueta H, Bisson R, Beck RD (2013) Rev Sci Instrum 84:053902

46. Scoles G (1988) Atomic and molecular beam methods. Oxford University Press, New York

47. Speller S, Kuntze J, Rauch T, Bömermann J, Huck M, Aschoff M, Heiland W (1996) Surf Sci 366:251

48. Tate MR, Gosalvez-Blanco D, Pullman DP, Tsekouras AA, Li YL, Yang JJ, Laughlin KB, Eckman SC, Bertino MF, Ceyer ST (1999) J Chem Phys 111:3679

49. Blöchl PE (1994) Phys Rev B 50:17953

50. Kresse G, Hafner J (1993) Phys Rev B 47:558

51. Kresse G, Hafner J (1994) Phys Rev B 49:14251

52. Kresse G, Furthmüller J (1996) Comput Mater Sci 6:15

53. Kresse G, Furthmüller J (1996) Phys Rev B 54:11169

54. Kresse G, Joubert D (1999) Phys Rev B 59:1758

55. https://cms.mpi.univie.ac.at/wiki/index.php/The_VASP_Manual

56. Perdew JP, Burke K, Ernzerhof M (1996) Phys Rev Lett 77:3865

57. Grimme S, Antony J, Ehrlich S, Krieg H (2010) J Chem Phys 132:154104

58. Klimeš J, Bowler DR, Michaelides A (2010) J Phys: Condens Matter 22:022201

59. Chen L, Ueta H, Bisson R, Beck RD (2012) Faraday Discuss 157:285

60. Oakes DJ, Mccoustra MRS, Chesters MA (1993) Faraday Discuss 96:325

61. Bădescu C, Jacobi K, Wang Y, Bedürftig K, Ertl G, Salo P, AlaNissila T, Ying SC (2003) Phys Rev B Condens Matter Mater Phys 68:205401

62. Fairbrother DH, Peng XD, Trenary M, Stair PC (1995) J Chem Soc Faraday Trans 91:3619

63. Deng R, Herceg E, Trenary M (2004) Surf Sci 573:310

64. Jacob T, Goddard WA III (2005) J Phys Chem B 109:297

65. Orita H, Inada Y (2005) J Phys Chem B 109:22469 
66. Walsh AJ, van Lent R, Auras SV, Gleeson MA, Berg OT, Juurlink LBF (2017) J Vac Sci Technol A Vac Surf Film 35:03E102

67. Xu J, Yates JT (1995) Surf Sci 327:193

68. Bisson R, Sacchi M, Beck RD (2010) J Chem Phys 132:094702

69. Brandt RK, Sorbello RS, Greenler RG (1992) Surf Sci 271:605

70. Chadwick H, Gutiérrez-González A, Beck RD, Kroes GJ (2019) J Chem Phys 150:124702

71. Calle-Vallejo F, Tymoczko J, Colic V, Vu QH, Pohl MD, Morgenstern K, Loffreda D, Sautet P, Schuhmann W, Bandarenka AS (2015) Science 350:185

72. Petersen MA, Jenkins SJ, King DA (2004) J Phys Chem B 108:5920

73. Olsen RA, Bădescu ŞC, Ying SC, Baerends EJ (2004) J Chem Phys 120:11852

74. Anghel AT, Wales DJ, Jenkins SJ, King DA (2005) Phys Rev B Condens Matter Mater Phys 71:2

75. Hammer B, Nørskov JK (1995) Surf Sci 343:211

76. Hammer B, Nørskov JK (1995) Nature 376:238
77. Hammer B, Nørskov JK (2000) Adv Catal 45:71

78. Watanabe K, Matsumoto Y (1997) Surf Sci 390:250

79. Killelea DR, Campbell VL, Shuman NS, Smith RR, Utz AL (2009) J Phys Chem C 113:20618

80. Ueta H, Chen L, Beck RD, Colón-Díaz I, Jackson B (2013) Phys Chem Chem Phys 15:20526

Publisher's Note Springer Nature remains neutral with regard to jurisdictional claims in published maps and institutional affiliations. 